\title{
Slow Open Dialectical Behavior Group Therapy for Adolescents and Parents: Comparison between Groups
}

\author{
Aranzazu Fernandez-Rivas ${ }^{1,2}$, Eva Sesma-Pardo,1,2, Iñaki Kerexeta, ${ }^{1,2}$, Aida Diaz-Cosgaya1, \\ Esther Vivanco ${ }^{1}$, Federico Carminati ${ }^{3,4}$, Miguel Angel Gonzalez Torres ${ }^{1,2}$, Claire Fouassier ${ }^{3,4}$, \\ François Martin ${ }^{5}$, Jacques Demongeot ${ }^{6}$, Giuliana Galli Carminati ${ }^{3,4,7^{*}}$ \\ ${ }^{1}$ Psychiatry Service, Basurto University Hospital-Osakidetza, Bilbao, Spain \\ ${ }^{2}$ Neurosciences Department, Basque Country University, Bilbao, Spain \\ ${ }^{3}$ Association pour le TRAvail Groupal Thérapeutique et Social (ASTRAG) and Simposietto, Geneva, Switzerland \\ ${ }^{4}$ Société Internationale de Psychanalyse Multidisciplinaire (SIPsyM), Geneva, Switzerland \\ ${ }^{5}$ Honorary Member of the French National Centre for Scientific Research (CNRS), Paris, France \\ ${ }^{6}$ AGEIS EA 7407, Faculté de Médecine, Université Grenoble Alpes, La Tronche, France \\ ${ }^{7}$ Seoul National University, Bundang Hospital (SNUBH), Seoul, Republic of Korea \\ Email: ^giuliana.gallicarminati@gmail.com
}

How to cite this paper: Fernandez-Rivas, A., Sesma-Pardo, E., Kerexeta, I., Diaz-Cosgaya, A., Vivanco, E., Carminati, F., Torres, M. A. G., Fouassier, C., Martin, F., Demongeot, J., \& Carminati, G. G. (2022). Slow Open Dialectical Behavior Group Therapy for Adolescents and Parents: Comparison between Groups. Psychology, 13, 1-26.

https://doi.org/10.4236/psych.2022.131001

Received: December 2, 2021

Accepted: January 11, 2022

Published: January 14, 2022

Copyright $\odot 2022$ by author(s) and Scientific Research Publishing Inc. This work is licensed under the Creative Commons Attribution International License (CC BY 4.0).

http://creativecommons.org/licenses/by/4.0/ (c) (i) Open Access

\begin{abstract}
Introduction: The study's objective is to explore the common behavior of the participants in four slow open groups taking part in a Dialectical Behavior Therapy (DBT) skills training. The experiment population consisted of two groups of adolescents and two of some of their parents or legal guardians. We compared the groups via their answers to the "absurd questionnaire" during the training sessions. Methods: the participants had to select one image in each of 50 pairs in a questionnaire ("absurd questionnaire"). In this experiment, we were able to administer a version of the questionnaire to the participants before forming the groups. We analyzed the differences between the four groups, considering their initial picture choices and how these evolved, the changes in the choices, the flux, and the answers' focus. Results: The presence of a questionnaire administered before the group experience allows us to distinguish between socio-cultural orientation and group effects. A strong orientation precedes the group formation, is partially lost during the group activity and is eventually recovered at the end of the group work. In addition, there are apparent similarities between the same age groups (parents and adolescents), while family ties seem to play a lesser role in shaping the group's behavior. Conclusions: The slow-open setting appears to render the groups more susceptible to the external environment. While we can observe the formation of a group identity distinguishable from the "clan loyalty" via a de-
\end{abstract}


crease in the initial orientation, this is short-lived, and the external environment asserts its eventual dominance. Family ties are less effective than generational kinship in shaping the groups' behavior.

\section{Keywords}

Dialectical Behavior Therapy (DBT), Group Dynamics in Young and Parents, Slow Open Group Work, Group Analysis, Psychophysics,

Unconscious Entanglement

\section{Introduction}

This work extends our investigation in the possibility of quantifying or, at the least, objectifying group dynamics (Fernandez-Rivas et al., 2020, 2021a, 2021b; Trojaola-Zapirain et al., 2014, 2015, 2016, 2019). We have already exposed the basic tenets that have led us to this research in the referenced papers, and therefore we will give here only a short reminder. The present work will compare the four groups, two composed of parents and two of adolescents, who attended the DBT skill group training.

Dialectical Behavioral Therapy (Linehan, 1993, 2015; Miller et al., 2017) has emerged as an effective transdiagnostic treatment for teenagers with emotional dysregulation and impulsivity. The Psychiatric Service of the Basurto University Hospital (Bilbao, Spain) has deployed a therapeutic system based on DBT with several modules, including adolescent and parent groups.

Carl Gustav Jung did not devote his attention explicitly to group phenomena. His emphasis on the process of individuation seems to relegate the "collective" to a state from which the individual must differentiate himself. Nevertheless, his concept of collective unconscious offers a precious theoretical frame to analyze and understand the "collective soul" (Jung, 1959) as the metaphorical place where the world of reality connects with the world of the soul (Jung, 1952, 1960).

The perception of the sensible evidence of these connections is what Jung has called "synchronicity" (Jung, 1952). Synchronicity is, according to Jung, an emotionally perceived correlation between an affective event, feeling or thought and an external fact that bears no evident relation of causality with each other.

In quantum mechanics, we can detect microscopic processes via their interaction with macroscopic devices that we can call detectors. This effect is what we indicate with "quantum amplification". Jung also employs the term amplification (Jung \& Hull, 1911) as the extension of the meaning of an image perceived in a dream via the patient's free association activity and the analogies between the image and similar representations in socio-cultural and historical contexts. According to Jung (Jung, 1962), it is only thanks to this hybrid process (personal and social) that the dream's meaning becomes accessible to interpretation. Thus, analogical reasoning based on the term amplification may suggest we consider unconscious mental processes such as dreams as "microscopic" quan- 
tum processes that we can detect and interpret only via their interaction with consciousness performing here an amplification and measurement process. This is one more case of the interesting analogies that we can find between quantum physics and psychodynamic.

When Jung met W. Pauli, a towering figure of $20^{\text {th }}$-century physics, they postulated that the concept of synchronicity was the psychological equivalent of the recently hypothesized quantum entanglement (Jung et al., 2001). Several authors have expanded on the possibility to draw parallels between psychology and quantum mechanics, giving rise to a new field of inquiry loosely known as psychophysics. This discipline explores the possibility of applying quantum mechanics concepts to studying the human soul. The essential tenet of this field is that we can describe consciousness by a universal field of quantum nature (Baaquie \& Martin, 2005; Conte et al., 2003; Orlov, 1982). Other authors have explored the relation of mind and matter in terms of the monistic implications of a unique theory explaining the behavior of both (Freeman \& Vitiello, 2016; Pitkänen, 2010). Several studies have looked for a physical location of quantum phenomena in the brain (Beck \& Eccles, 1992; Galli Carminati et al., 2017; Grinberg-Zylberbaum et al., 1994; Hameroff \& Penrose, 1996; Sabbadini \& Vitiello, 2019). Quantum Information Theory has been proposed as an attractive framework to describe mental phenomena (Cerf \& Adami, 1998; Martin et al., 2009, 2018; Martin \& Galli Carminati, 2009). Other works are of more general nature and revisit the epistemological foundations of quantum mechanics in the light of its supposed connection with the explication of mental activity (Marshall, 1989; Martin \& Galli Carminati, 2009; Penrose \& Gardner, 1989; Penrose, 1994; Vitiello, 2003; Zurek, 1981).

Wilfrid Bion (Bion, 1961) was the first to develop a psychological theory of the groups by elaborating the "basic assumptions", i.e., universal principles regulating the working of all human assemblies. Other authors extended and deepened his works describing the complex network of interactions within and without the group (Foulkes, 1964; Vergopoulos, 1983), and even proposed that the individual psyche itself has a "group" nature (Kaës, 2010). However, Bion's principal tenet is that we should not consider the members of a group governed by the "basic assumptions" simply as individuals but rather as the expression of the group's psychical entity (Bion, 1961). This is precisely what happens in the microscopic world when quantum entities interact and form a collective "entangled" state. In this case, the behavior of every single entity can only be studied and understood as an expression of the global state of the system (Aspect et al., 1982; Bell, 1964, 1966; Bohr, 1935; Einstein et al., 1935; Richens et al., 2017; Schrödinger, 1935, 1936).

Starting from this tantalizing analogy, some of the authors have considered the possibility to study the group behavior as a multi-body entangled system (Galli Carminati \& Carminati, 2006; Galli Carminati \& Martin, 2008; Martin et al., 2009; Martin, Carminati \& Galli Carminati, 2010; Martin et al., 2018). This hypothesis has led to the formulation of the "absurd experiment" that is the subject of this paper, and that has already been performed on different psychodynam- 
ics groups (Fernandez-Rivas et al., 2020, 2021b, 2021a; Trojaola-Zapirain et al., 2014, 2015, 2016, 2019).

The rationale for this study is to try to determine whether the supposed entanglement between the unconscious during a group experience is measurable in an "objective" and quantifiable manner. We presume that the group situation "amplifies" the interaction between the unconscious so that it becomes observable at the "macroscopic" level. Given the paramount importance of our unconscious in all forms of normal and pathological behavior, a positive answer to this question would be of high theoretical and possibly therapeutical relevance.

In this work, we analyze the differences between four groups, two composed of adolescents and two of their parents, who were following a Dialectical Behavior Therapy (DBT) skills training at the Psychiatric Service of the Basurto University Hospital in Bilbao, Spain.

\section{Materials and Methods}

\subsection{Participants}

The groups studied in this paper are the same as in (Fernandez-Rivas et al., 2021a, 2021b), and, for clarity's sake, we will repeat the description of the experimental conditions here. We have included in this study two groups of adolescents and two of some of their respective parents or legal responsible (hereon Parents). They all took part in Dialectical Behavior Therapy (DBT) skill training consisting of a weekly 2-hours session for the adolescents and a weekly 1.5 hours session for the parents. The adolescent groups took place in the same period as their parents' groups (albeit on different days of the week). We present in Table 1 the demographical data of the participants. The adolescents participating in these groups suffered from behavioral problems and presented impulse-control disorders or emotional dysregulation.

The study began after the Basurto University Hospital Ethics Committee (Bilbao, Spain) approval in conformity with the Helsinki Declaration for research with human subjects. All participants gave written informed consent after receiving oral and written information about the experiment, and specifically for adolescents, both the participant and their parents or legal tutor signed informed consents. All participant data were coded to be completely anonymous, including the researchers analyzing the data.

\subsection{Procedure}

DBT training concentrates on mindfulness, distress tolerance, emotion regulation, effective interpersonal communication, and choosing the middle path. The adolescents meet for two hours weekly and the parents for 1.5 hours weekly. Two therapists supervised each group in a "slow-open" setting, meaning participants could join and leave the groups during the training.

Before joining the training, all participants (adolescents and parents) attended an evaluation and information interview on the group's methodology and the 
research, during which they completed the informed consent and the questionnaire number "zero" (with one exception). Since we conducted this interview at different times, we have arbitrarily set the time of the first interview one month before the first group. In addition, we collected sociodemographic data on adolescents (see Table 1).

We assigned an identification code to each participant to hide his identity. We have already described in detail the general setting of this experiment in previous publications (Fernandez-Rivas et al., 2020, 2021b, 2021a; Trojaola-Zapirain et al., 2014, 2015, 2016, 2019). For completeness, we recall that the questionnaires contained 50 pairs of figures. The pairs were randomly reshuffled each time we administered the questionnaire to avoid ordinal memory bias. We required participants to choose one picture from each pair in three minutes. We have selected to use images to minimize the socio-cultural bias potentially associated with a word test (Zanello et al., 2004). Figure 1 shows a page from the questionnaire with fictitious picture selections.

In what follows, PG1 is the first parent group, PG2 the second parent group, YG1 the first adolescent group, and YG2 is the second adolescent group. The

Table 1. Demographic and social group composition of the four groups participating in this study.

\begin{tabular}{ccccc}
\hline & Adolescent G1 & Adolescent G2 & Parents G1 & Parents G2 \\
\hline Total & 21 & 16 & 25 & 19 \\
Female & $14(66.7 \%)$ & $14(87.5 \%)$ & $18(72 \%)$ & $11(57.9 \%)$ \\
Average age & 15.6 & 16.4 & & \\
1Q-3Q & $14.9-16.5$ & $15.3-17.4$ & \\
Biological Family & 8 & 7 & \\
Adoptive Family & 1 & 2 & \\
Single Parent & 10 & 6 & \\
Other living situations & 2 & 1 & \\
Undergrad education & 17 & 9 & \\
Graduate education & 4 & 6 & \\
Postgraduate education & & 1 & \\
\hline
\end{tabular}
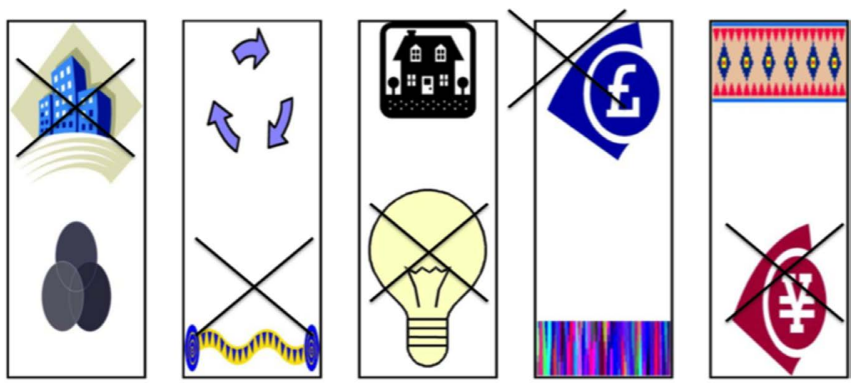

Figure 1. Example of a questionnaire's page with fictitious. 
training duration was 43 sessions for PG1, 31 for PG2, 43 for YG1, and 27 for YG2.

As we can see in Figures 2-4, participation was not very regular, particularly for the adolescent groups after the fifth session.

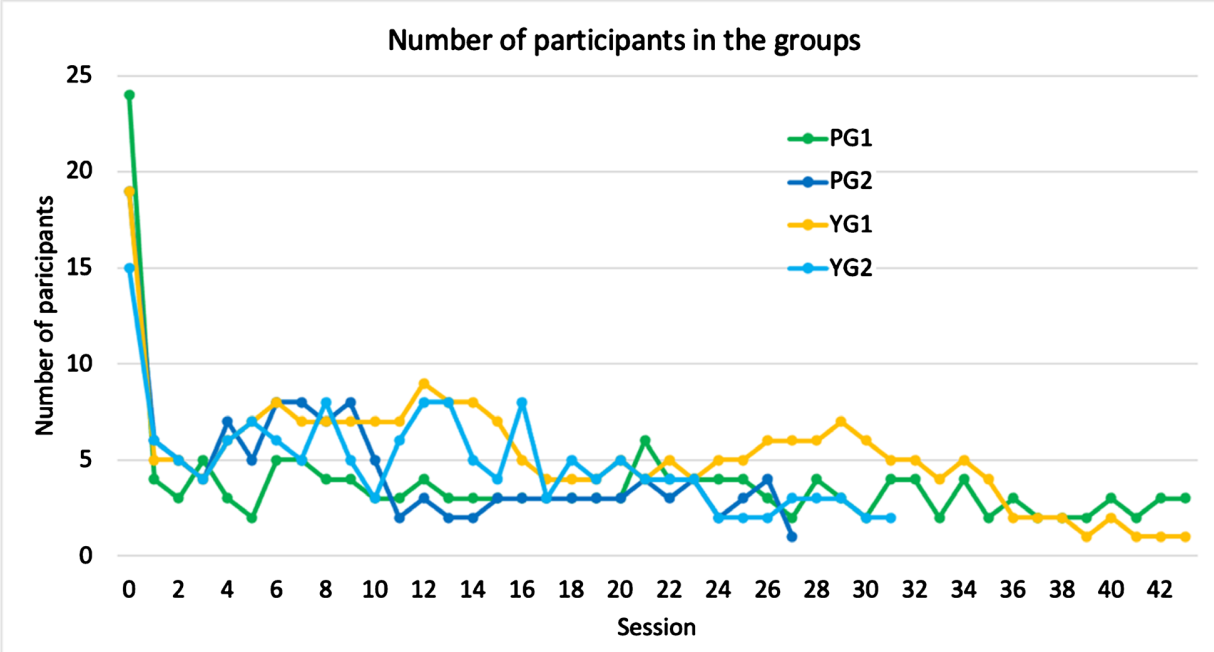

Figure 2. Number of participants in the different sessions.

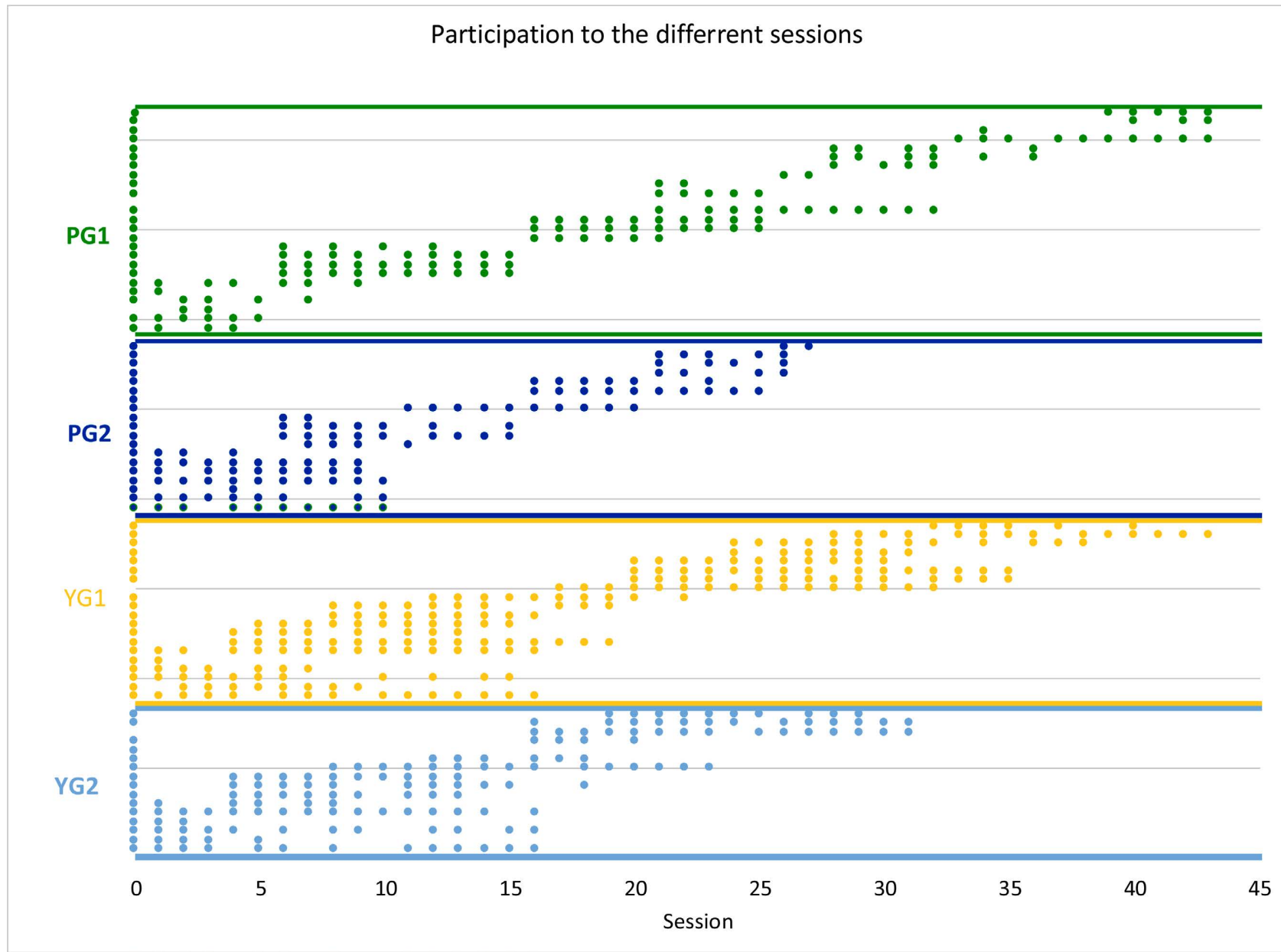

Figure 3. Participation of the trainees at the different sessions. 


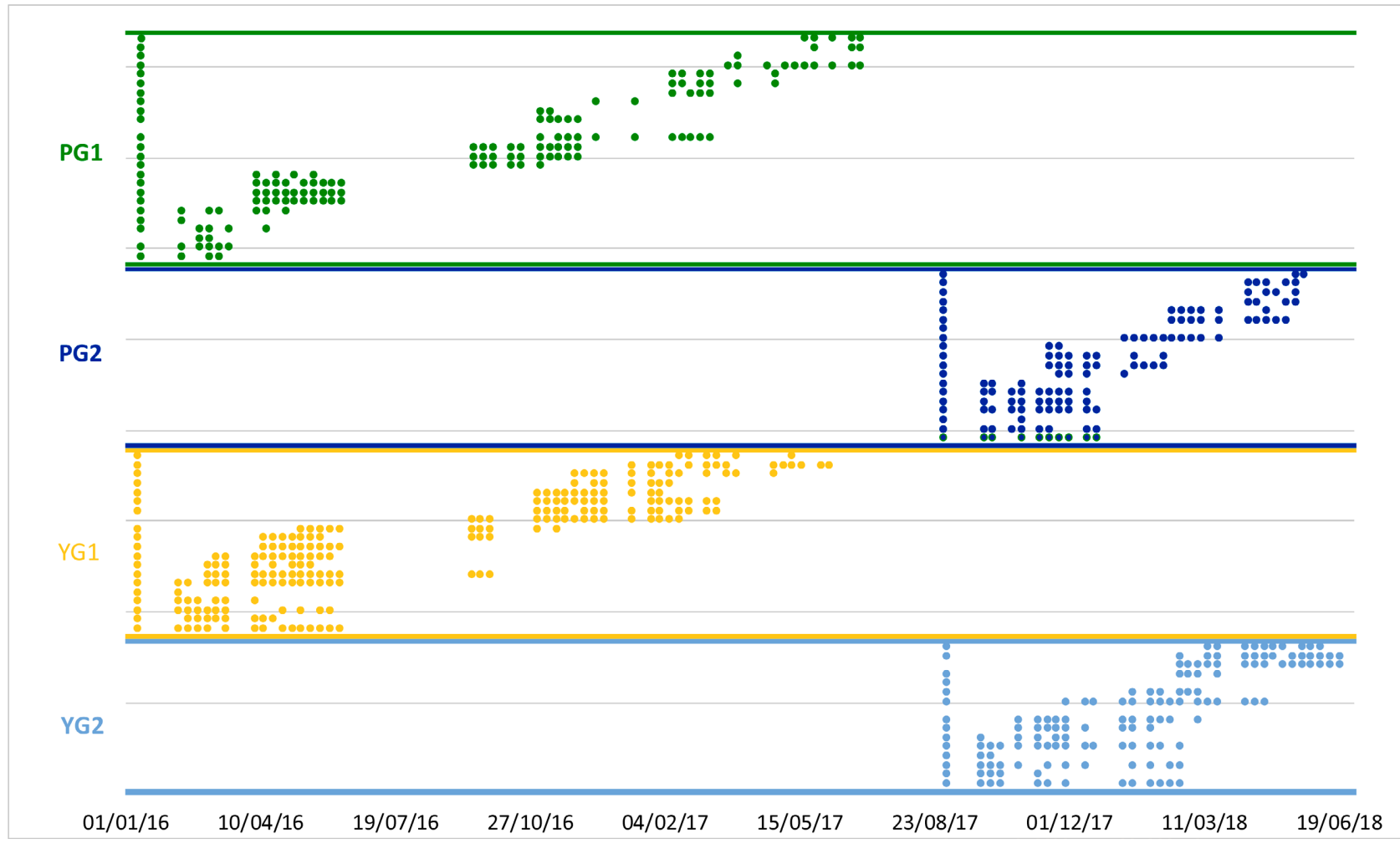

Figure 4. Evolution of the attendance to the training versus time.

\subsection{Data Analysis}

For each pair of pictures, we indicate with $\mathrm{A}\left(\mathrm{A}_{p} i=1.50\right)$ the most often chosen in the questionnaire passed before the beginning of the training (questionnaire $0)$. Then, we label the other picture as $\mathrm{B}\left(\mathrm{B}_{i}, i=1.50\right)$.

We have compiled frequency tables for each pair of images and each session for the four groups. We have concentrated our attention on the evolution of the whole group rather than on the single participant change of choices. Therefore, we have studied the evolution of the A's picture frequencies irrespectively of the single participant's choice.

Since these are open groups, we did not consider it appropriate to correct completely missing data. We did, however, correct for incorrect or missing (forgotten) selections in existing questionnaires. We did this with the LOCF (Last Observation Carry Forward (Hamer \& Simpson, 2009)) procedure. In case of a missing answer, we used that of the previous session or the one before it if this too was missing, and so on. If the faulty answer was in questionnaire 0 , we selected the picture randomly. We report in Table 2 the number of corrections.

We compared the percentage of the " $\mathrm{A}$ "'s picture choice for the 50 questions in each session with a Mann-Whitney test.

\section{Results}

\subsection{Comparison of the Groups via the Most Chosen Picture}

We begin with comparing the development during the training of the frequency 
Table 2. Data corrected with the LOCF procedure.

\begin{tabular}{cccc}
\hline Group & Total valid answers & Answers corrected with LOCF & $\%$ \\
\hline PG1 & 8148 & 101 & $1.2 \%$ \\
PG2 & 6406 & 95 & $1.5 \%$ \\
YG1 & 11,131 & 69 & $0.6 \%$ \\
YG2 & 7037 & 63 & $0.9 \%$ \\
\hline
\end{tabular}

A's selections for each pair of the four groups.

As noticed in our previous publications (Fernandez-Rivas et al., 2020, 2021b, 2021a; Trojaola-Zapirain et al., 2014, 2015, 2016, 2019), a salient characteristic of the answers to the $0^{\text {th }}$ questionnaire is the intense "polarization" of the frequency of A's choices with percentages of 70.6\% (PG1), 70.5\% (PG2), 63.7\% (YG1), and $64.7 \%$ (YG2). This trend is similar to what we found in a previous study of DBT closed groups (Fernandez-Rivas et al., 2020).

Interestingly, the parent groups PG1 and PG2 show an increase in the choice of the initial preferred image $(+4.1 \%$ and $+11.5 \%$, respectively). In contrast, the adolescent groups YG1 and YG2 present a diminution $(-11.7 \%$ and $-5.6 \%$, respectively) at the end of the training, with final percentages increased to $74.7 \%$ for PG1 and $82 \%$ for PG2 and reduced to 52\% for YG1, and 56\% for YG2.

For each pair of groups (i.e., PG1 vs. PG2, PG1 vs. YG1, PG1 vs. YG2, PG2 vs. YG1, PG2 vs. YG2, and YG1 vs. YG2), we have compared with a Mann-Whitney test the percentage of the choice of the " $\mathrm{A}$ " picture for the 50 questions in each session. Table 3 and Figure 5 report the result of the comparison.

Table 4 summarizes the frequency of significant differences between the groups.

The minimum number of statistically significant differences in the choice of image A is inYG1 vs. YG2 (19\%), followed by PG1 vs. PG2 (32\%). We note that the adolescents of groups 1 and 2 (see Figure 4) attended their therapy in non-overlapping periods, and the same is true for the parent groups 1 and 2. The differences between parents and adolescents are more significant within the same families: $50 \%$ for PG1 vs. YG1 and $68 \%$ for PG2 vs. YG2. The statistical differences between parents and adolescents in different families are still larger: $75 \%$ for PG1 vs. YG2 and $68 \%$ for PG2 vs. YG1.

The timing of the statistically significant differences during the therapy is very variable, and they do not show a common discernable pattern.

\subsection{Comparison of the Groups' Evolution of the Transitions of Choices}

Now analyze the evolution of the transition between A and B choices in the different groups. First, we tally the number of participants who changed their choice from A to B or from B to A in each pair of consecutive sessions. Then, we label these frequencies with the number of the second session. Therefore, the 
A. Fernandez-Rivas et al.

Table 3. Comparison of the frequency of choice of the " $A$ " picture for the same sessions in the different groups. The value reported is the Mann-Whitney statistics probability. The cells in red show statistical differences $(p<0.05)$.

\begin{tabular}{|c|c|c|c|c|c|c|c|c|c|c|c|c|c|}
\hline \multicolumn{14}{|c|}{ A } \\
\hline Session & $\begin{array}{l}\text { PG1- } \\
\text { PG2 }\end{array}$ & $\begin{array}{l}\text { PG1- } \\
\text { YG1 }\end{array}$ & $\begin{array}{l}\text { PG1- } \\
\text { YG2 }\end{array}$ & $\begin{array}{l}\text { PG2- } \\
\text { YG1 }\end{array}$ & $\begin{array}{l}\text { PG2- } \\
\text { YG2 }\end{array}$ & $\begin{array}{l}\text { YG1- } \\
\text { YG2 }\end{array}$ & Session & $\begin{array}{l}\text { PG1- } \\
\text { PG2 }\end{array}$ & $\begin{array}{l}\text { PG1- } \\
\text { YG1 }\end{array}$ & $\begin{array}{l}\text { PG1- } \\
\text { YG2 }\end{array}$ & $\begin{array}{l}\text { PG2- } \\
\text { YG1 }\end{array}$ & $\begin{array}{l}\text { PG2- } \\
\text { YG2 }\end{array}$ & $\begin{array}{l}\text { YG1- } \\
\text { YG2 }\end{array}$ \\
\hline A00 & 0.751 & 0.003 & 0.018 & 0.002 & 0.009 & 0.401 & A22 & 0.494 & 0.079 & 0.001 & 0.000 & 0.000 & 0.179 \\
\hline A01 & 0.105 & 0.098 & 0.001 & 0.257 & 0.337 & 0.388 & A23 & 0.427 & 0.087 & 0.314 & 0.020 & 0.097 & 0.442 \\
\hline $\mathrm{A} 02$ & 0.341 & 0.044 & 0.001 & 0.078 & 0.002 & 0.154 & A24 & 0.093 & 0.326 & 0.957 & 0.015 & 0.154 & 0.530 \\
\hline A03 & 0.474 & 0.066 & 0.000 & 0.268 & 0.000 & 0.016 & A25 & 0.205 & 0.164 & 0.511 & 0.001 & 0.022 & 0.708 \\
\hline A04 & 0.469 & 0.019 & 0.076 & 0.034 & 0.140 & 0.499 & A26 & 0.021 & 0.010 & 0.037 & 0.000 & 0.000 & 0.971 \\
\hline A05 & 0.047 & 0.002 & 0.001 & 0.002 & 0.009 & 0.691 & $\mathrm{~A} 27$ & 0.000 & 0.119 & 0.834 & 0.000 & 0.000 & 0.147 \\
\hline A06 & 0.009 & 0.000 & 0.001 & 0.052 & 0.056 & 0.952 & A28 & & 0.016 & 0.018 & & & 0.904 \\
\hline A07 & 0.055 & 0.003 & 0.000 & 0.070 & 0.001 & 0.142 & A29 & & 0.024 & 0.872 & & & 0.026 \\
\hline A08 & 0.001 & 0.000 & 0.000 & 0.012 & 0.034 & 0.310 & A30 & & 0.058 & 0.029 & & & 0.435 \\
\hline A09 & 0.003 & 0.000 & 0.000 & 0.012 & 0.001 & 0.602 & A31 & & 0.208 & 0.262 & & & 0.883 \\
\hline A 10 & 0.017 & 0.578 & 0.280 & 0.001 & 0.000 & 0.038 & A32 & & 0.114 & & & & \\
\hline A11 & 0.236 & 0.000 & 0.000 & 0.004 & 0.014 & 0.745 & A33 & & 0.139 & & & & \\
\hline $\mathrm{A} 12$ & 0.002 & 0.000 & 0.000 & 0.381 & 0.495 & 0.390 & A34 & & 0.350 & & & & \\
\hline A13 & 0.363 & 0.000 & 0.000 & 0.020 & 0.009 & 0.832 & A35 & & 0.001 & & & & \\
\hline A14 & 0.914 & 0.000 & 0.000 & 0.000 & 0.004 & 0.347 & A36 & & 0.244 & & & & \\
\hline A 15 & 0.021 & 0.000 & 0.002 & 0.000 & 0.054 & 0.223 & A37 & & 0.428 & & & & \\
\hline A16 & 0.553 & 0.002 & 0.000 & 0.001 & 0.000 & 0.569 & A38 & & 0.001 & & & & \\
\hline A 17 & 0.499 & 0.128 & 0.001 & 0.320 & 0.001 & 0.011 & A39 & & 0.149 & & & & \\
\hline A18 & 0.523 & 0.002 & 0.011 & 0.001 & 0.007 & 0.775 & A40 & & 0.000 & & & & \\
\hline A19 & 0.228 & 0.001 & 0.007 & 0.002 & 0.015 & 0.446 & A41 & & 0.099 & & & & \\
\hline A20 & 0.568 & 0.832 & 0.035 & 0.397 & 0.002 & 0.003 & A42 & & 0.097 & & & & \\
\hline $\mathrm{A} 21$ & 0.140 & 0.787 & 0.014 & 0.152 & 0.001 & 0.007 & A43 & & 0.076 & & & & \\
\hline
\end{tabular}
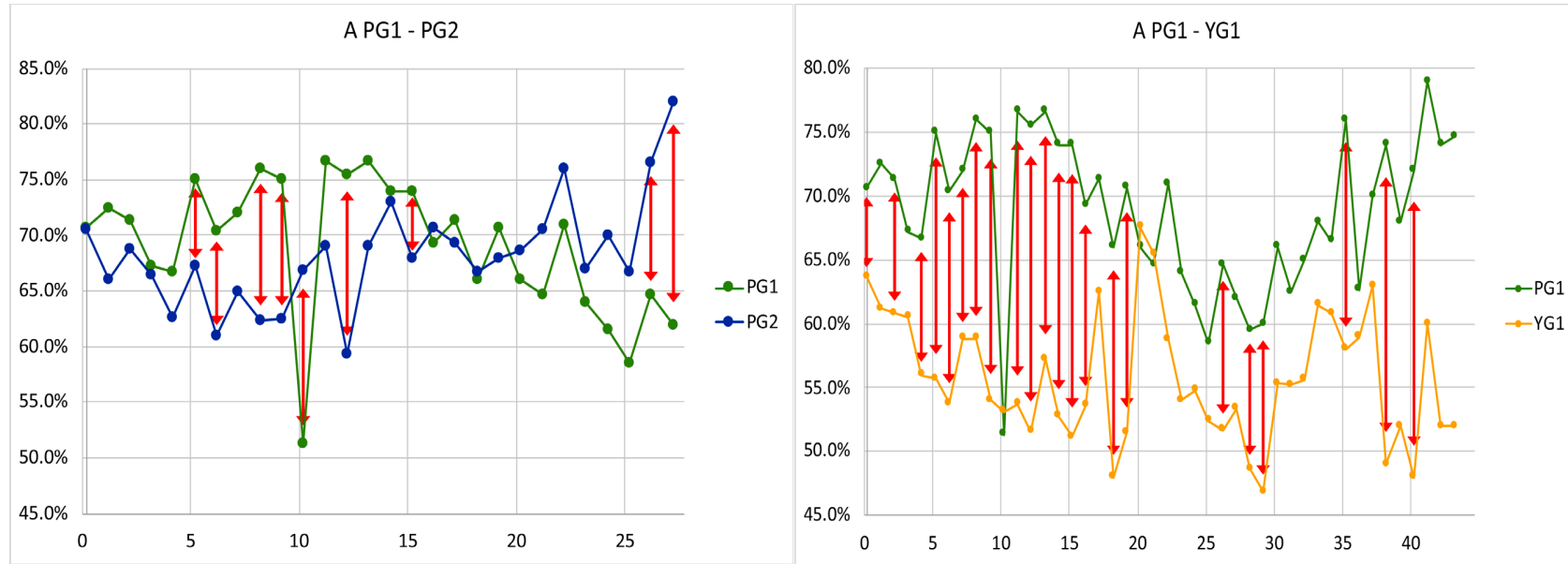


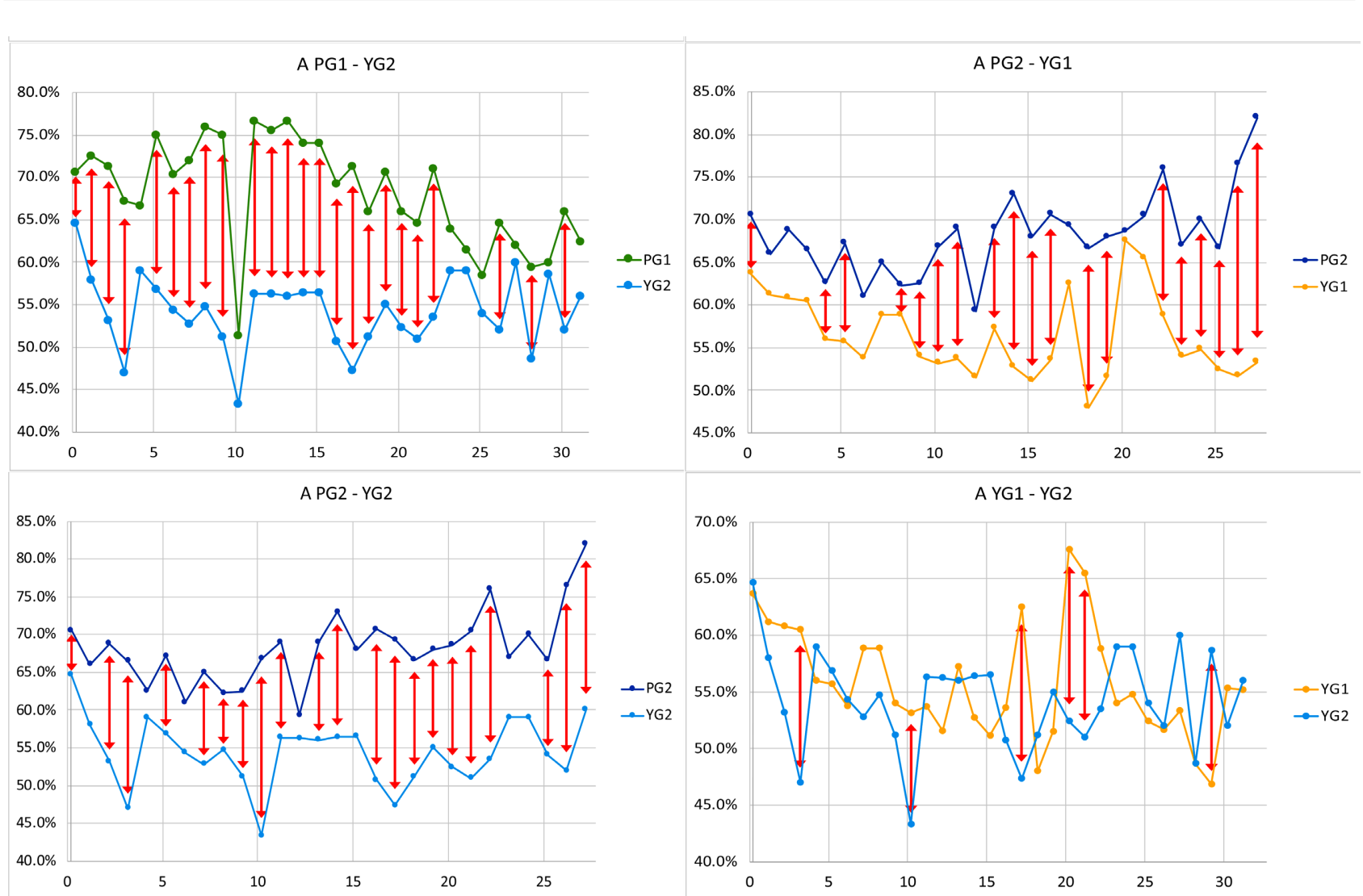

Figure 5. Comparison of the A choice during the various sessions for the four groups. The red arrows indicate where A's choice is statistically different (Mann-Whitney $p<0.05)$ between the two groups.

Table 4. statistically significant differences between sessions for the different groups for the frequency of choice of the A picture. We compared the maximum number of common sessions for each pair of groups via a Mann-Whitney test, and we report the number of sessions for which $p<0.05$.

\begin{tabular}{cccc}
\hline Comparison & N sess & N sig & \% diff \\
\hline PG1-PG2 & 28 & 9 & $32 \%$ \\
PG1-YG1 & 44 & 22 & $50 \%$ \\
PG1-YG2 & 32 & 24 & $75 \%$ \\
PG2-YG1 & 28 & 19 & $68 \%$ \\
PG2-YG2 & 28 & 19 & $68 \%$ \\
YG1-YG2 & 32 & 6 & $19 \%$ \\
\hline
\end{tabular}

frequency of changes $(\mathrm{A} \rightarrow \mathrm{B}$ or $\mathrm{B} \rightarrow \mathrm{A}$ ) indicated with $n$ is between sessions $\mathrm{n}-$ 1 and $n$. Table 5 and Figure 6 report the transitions $A \rightarrow B$.

Table 5 and Figure 6 show the result of the Mann-Whitney comparison of the choice transition from the " $\mathrm{A}$ " to the " $\mathrm{B}$ " picture for the corresponding sessions of each group pair (PG1 vs. PG2, PG1 vs. YG1, PG1 vs. YG2, PG2 vs. YG1, PG2 vs. YG2, and YG1 vs. YG2).

Table 7 reports the number and frequency of statistical differences between 
A. Fernandez-Rivas et al.

Table 5. Comparison of the choice transition from the "A" to the "B" picture for the corresponding sessionsof each group pair. The value reported is the Mann-Whitney statistics probability. The cells in red show statistical differences $(p<0.05)$.

\begin{tabular}{|c|c|c|c|c|c|c|c|c|c|c|c|c|c|}
\hline \multicolumn{14}{|c|}{$A \rightarrow B$} \\
\hline Session & $\begin{array}{l}\text { PG1- } \\
\text { PG2 }\end{array}$ & $\begin{array}{l}\text { PG1- } \\
\text { YG1 }\end{array}$ & $\begin{array}{l}\text { PG1- } \\
\text { YG2 }\end{array}$ & $\begin{array}{l}\text { PG2- } \\
\text { YG1 }\end{array}$ & $\begin{array}{l}\text { PG2- } \\
\text { YG2 }\end{array}$ & $\begin{array}{l}\text { YG1- } \\
\text { YG2 }\end{array}$ & Session & $\begin{array}{l}\text { PG1- } \\
\text { PG2 }\end{array}$ & $\begin{array}{l}\text { PG1- } \\
\text { YG1 }\end{array}$ & $\begin{array}{l}\text { PG1- } \\
\text { YG2 }\end{array}$ & $\begin{array}{l}\text { PG2- } \\
\text { YG1 }\end{array}$ & $\begin{array}{l}\text { PG2- } \\
\text { YG2 }\end{array}$ & $\begin{array}{l}\text { YG1- } \\
\text { YG2 }\end{array}$ \\
\hline $\mathrm{A} 00-\mathrm{A} 01$ & 0.141 & 0.412 & 0.016 & 0.127 & 0.331 & 0.021 & A22-A23 & 0.952 & 0.000 & 0.243 & 0.128 & 0.957 & 0.065 \\
\hline $\mathrm{A} 01-\mathrm{A} 02$ & 0.002 & 0.001 & 0.000 & 0.149 & 0.018 & 0.593 & A23-A24 & 0.827 & 0.144 & 0.525 & 0.762 & 0.412 & 0.586 \\
\hline $\mathrm{A} 02-\mathrm{A} 03$ & 0.775 & 0.529 & 0.034 & 0.213 & 0.102 & 0.001 & A24-A25 & 0.209 & 0.000 & 0.001 & 0.003 & 0.120 & 0.000 \\
\hline A03-A04 & 0.323 & 0.241 & 0.565 & 0.478 & 0.911 & 0.216 & A25-A26 & 0.512 & 0.000 & 0.000 & 0.001 & 0.011 & 0.000 \\
\hline A04-A05 & 0.000 & 0.000 & 0.000 & 0.579 & 0.067 & 0.312 & A26-A27 & 0.036 & 0.000 & 0.160 & 0.000 & 0.691 & 0.000 \\
\hline A05-A06 & 0.000 & 0.000 & 0.000 & 0.544 & 0.094 & 0.280 & A27-A28 & & 0.000 & 0.000 & & & 0.463 \\
\hline A06-A07 & 0.018 & 0.002 & 0.000 & 0.386 & 0.016 & 0.030 & A28-A29 & & 0.000 & 0.050 & & & 0.012 \\
\hline A07-A08 & 0.000 & 0.000 & 0.000 & 0.191 & 0.175 & 0.979 & A29-A30 & & 0.000 & 0.002 & & & 0.525 \\
\hline A08-A09 & 0.000 & 0.000 & 0.000 & 0.010 & 0.052 & 0.235 & A30-A31 & & 0.000 & 0.626 & & & 0.159 \\
\hline A $09-A 10$ & 0.001 & 0.017 & 0.436 & 0.030 & 0.001 & 0.216 & A31-A32 & & 0.010 & & & & \\
\hline A10-A 11 & 0.002 & 0.000 & 0.005 & 0.000 & 0.000 & 0.319 & A32-A33 & & 0.443 & & & & \\
\hline A $11-\mathrm{A} 12$ & 0.594 & 0.000 & 0.000 & 0.000 & 0.000 & 0.008 & A33-A34 & & 0.004 & & & & \\
\hline A12-A13 & 0.730 & 0.000 & 0.000 & 0.000 & 0.000 & 0.508 & A34-A35 & & 0.000 & & & & \\
\hline A13-A14 & 0.673 & 0.000 & 0.000 & 0.000 & 0.000 & 0.078 & A35-A36 & & 0.079 & & & & \\
\hline A14-A15 & 0.160 & 0.000 & 0.000 & 0.000 & 0.003 & 0.134 & A36-A37 & & 0.009 & & & & \\
\hline A $15-A 16$ & 0.603 & 0.000 & 0.000 & 0.057 & 0.119 & 0.284 & A37-A38 & & 0.036 & & & & \\
\hline A16-A17 & 0.027 & 0.416 & 0.003 & 0.134 & 0.459 & 0.036 & A38-A39 & & 0.036 & & & & \\
\hline A17-A18 & 0.370 & 0.000 & 0.244 & 0.001 & 0.638 & 0.010 & A39-A40 & & 0.929 & & & & \\
\hline A18-A19 & 0.088 & 0.000 & 0.929 & 0.114 & 0.619 & 0.006 & $\mathrm{~A} 40-\mathrm{A} 41$ & & 0.081 & & & & \\
\hline A19-A20 & 0.179 & 0.011 & 0.000 & 0.025 & 0.299 & 0.000 & A41-A42 & & 0.828 & & & & \\
\hline A20-A21 & 0.156 & 0.000 & 0.005 & 0.022 & 0.064 & 0.868 & A $42-A 43$ & & 0.622 & & & & \\
\hline A21-A22 & 0.083 & 0.000 & 0.002 & 0.001 & 0.004 & 0.583 & & & & & & & \\
\hline
\end{tabular}
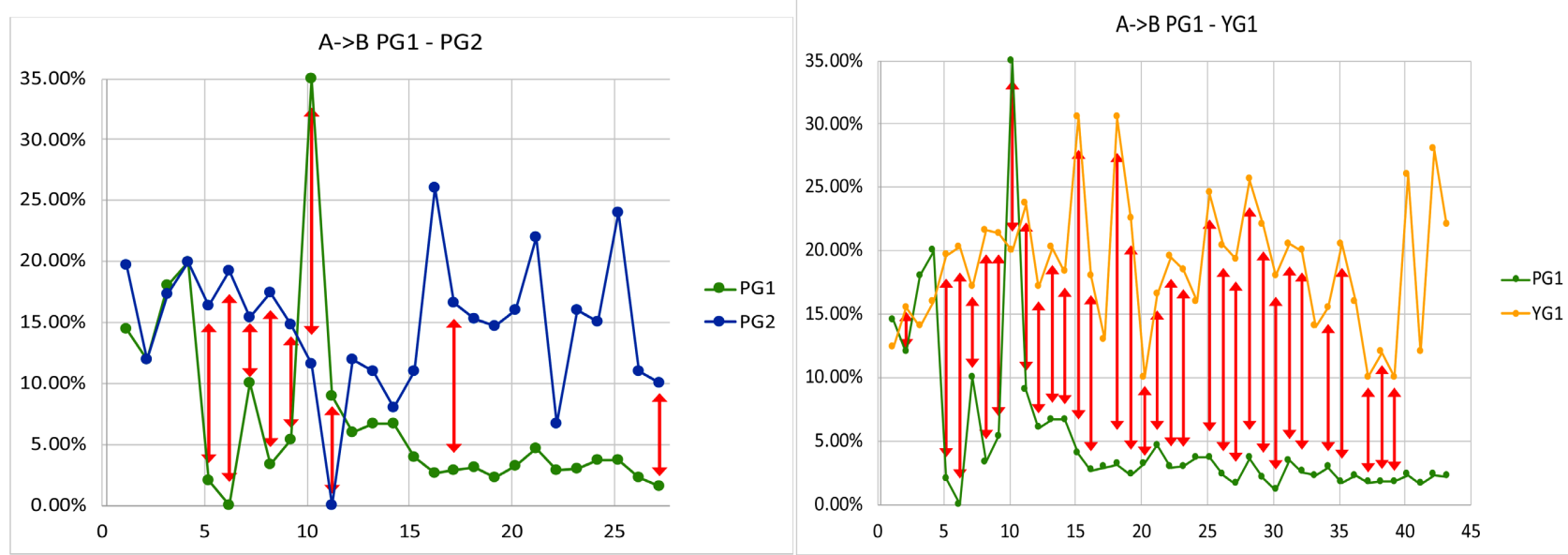


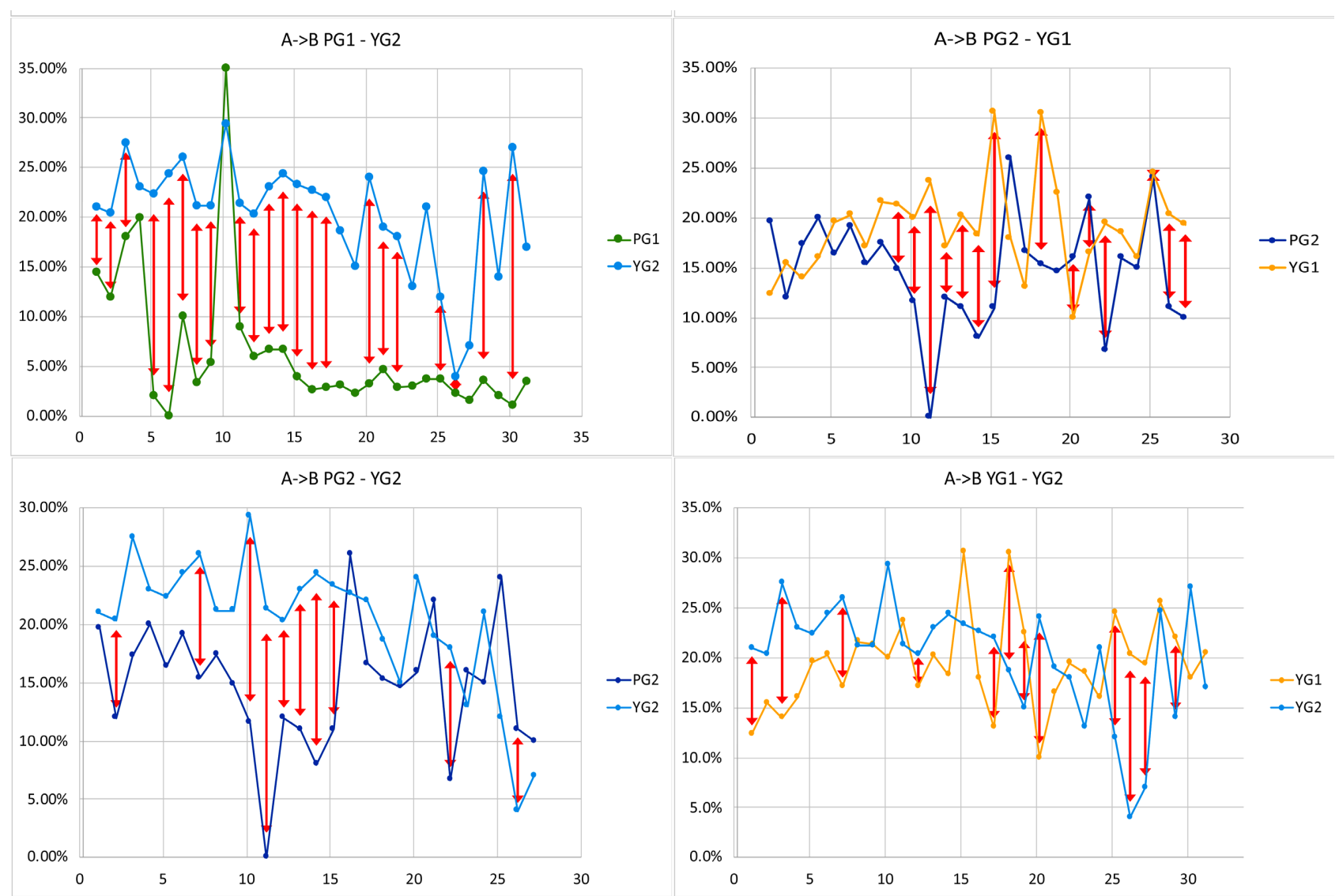

Figure 6. Comparison of the choice transition from the "A" to the "B" picture for the corresponding sessions of each group pair. The red arrows indicate where the transitions $\mathrm{A} \rightarrow \mathrm{B}$ are statistically different (Mann-Whitney $p<0.05)$ between the two groups.

the groups for the transitions $\mathrm{A} \rightarrow \mathrm{B}$. We find a trend like the choice of $\mathrm{A}$ for the age groups: the smaller number of statistical differences is for YG1 vs. YG2 (35\%) and PG1 vs. PG2 (37\%). For the same "familial frame" in the two groups, the differences between parents and adolescents are $74 \%$ for PG1 vs. YG1 and $37 \%$ for PG2 vs. YG2. The statistical differences between parents and adolescents in different "familial frames" are $71 \%$ for PG1 vs. YG2 and 52\% for PG2 vs. YG1.

We performed the same analysis for the transitions between $\mathrm{B}$ and A pictures for the four groups. Table 6 and Figure 7 report the results, and Table 8 shows the frequency of statistically significant differences between the groups.

Considering the age group, the trend of the differences in the changes $B \rightarrow A$ is partially similar to that of A's choice and A $\rightarrow$ B's transitions. The smaller number of statistical differences is for YG1 vs. YG2 (39\%), but for PG1 vs. PG2 the number of differences (48\%) is larger than for PG2 vs. YG1 (40\%). Considering the same "familial frame" for the groups G1 and G2, the differences between parents and adolescents are $62 \%$ for PG1 vs. YG1 and 55\% for PG2 vs. YG2, not clearly distinguished from the different "familial frames," 74\% for PG1 vs. YG2 and $40 \%$ for PG2 vs. YG1.

If the changes $\mathrm{A} \rightarrow \mathrm{B}$ and $\mathrm{B} \rightarrow \mathrm{A}$ were simple stochastic fluctuations, their respective distributions should be statistically indistinguishable. A difference in the 
A. Fernandez-Rivas et al.

Table 6. Comparison of the choice transition from the " $\mathrm{B}$ " to the " $\mathrm{A}$ " picture for the corresponding sessions of each group pair. The value reported is the Mann-Whitney statistics probability. The cells in red show statistical differences $(p<0.05)$.

\begin{tabular}{|c|c|c|c|c|c|c|c|c|c|c|c|c|c|}
\hline \multicolumn{14}{|c|}{$\mathrm{B} \rightarrow \mathrm{A}$} \\
\hline Session & $\begin{array}{l}\text { PG1- } \\
\text { PG2 }\end{array}$ & $\begin{array}{l}\text { PG1- } \\
\text { YG1 }\end{array}$ & $\begin{array}{l}\text { PG1- } \\
\text { YG2 }\end{array}$ & $\begin{array}{l}\text { PG2- } \\
\text { YG1 }\end{array}$ & $\begin{array}{l}\text { PG2- } \\
\text { YG2 }\end{array}$ & $\begin{array}{l}\text { YG1- } \\
\text { YG2 }\end{array}$ & Session & $\begin{array}{l}\text { PG1- } \\
\text { PG2 }\end{array}$ & $\begin{array}{l}\text { PG1- } \\
\text { YG1 }\end{array}$ & $\begin{array}{l}\text { PG1- } \\
\text { YG2 }\end{array}$ & $\begin{array}{l}\text { PG2- } \\
\text { YG1 }\end{array}$ & $\begin{array}{l}\text { PG2- } \\
\text { YG2 }\end{array}$ & $\begin{array}{l}\text { YG1- } \\
\text { YG2 }\end{array}$ \\
\hline $\mathrm{A} 00-\mathrm{A} 01$ & 0.000 & 0.739 & 0.010 & 0.000 & 0.136 & 0.154 & A22-A23 & 0.157 & 0.027 & 0.047 & 0.000 & 0.116 & 0.199 \\
\hline A01-A02 & 0.000 & 0.000 & 0.035 & 0.180 & 0.737 & 0.520 & A23-A24 & 0.939 & 0.052 & 0.491 & 0.001 & 0.001 & 0.003 \\
\hline A02-A03 & 0.059 & 0.802 & 0.000 & 0.059 & 0.022 & 0.063 & A $24-A 25$ & 0.439 & 0.002 & 0.962 & 0.000 & 0.000 & 0.000 \\
\hline A03-A04 & 0.004 & 0.533 & 0.036 & 0.487 & 0.412 & 0.709 & A $25-A 26$ & 0.641 & 0.000 & 0.151 & 0.000 & 0.002 & 0.000 \\
\hline A04-A05 & 0.000 & 0.000 & 0.000 & 0.901 & 0.007 & 0.000 & A26-A27 & 0.001 & 0.000 & 0.055 & 0.000 & 0.003 & 0.000 \\
\hline A05-A06 & 0.065 & 0.000 & 0.000 & 0.950 & 0.522 & 0.000 & A $27-A 28$ & & 0.000 & 0.585 & & & 0.100 \\
\hline A06-A07 & 0.000 & 0.000 & 0.000 & 0.124 & 0.540 & 0.000 & A $28-A 29$ & & 0.000 & 0.027 & & & 0.636 \\
\hline A07-A08 & 0.000 & 0.000 & 0.000 & 0.139 & 0.883 & 0.000 & A29-A30 & & 0.000 & 0.585 & & & 0.811 \\
\hline A08-A09 & 0.000 & 0.000 & 0.000 & 0.000 & 0.235 & 0.011 & A $30-A 31$ & & 0.000 & 0.406 & & & 0.136 \\
\hline A09-A10 & 0.000 & 0.000 & 0.003 & 0.000 & 0.216 & 0.002 & A $31-A 32$ & & 0.586 & & & & \\
\hline A10-A11 & 0.000 & 0.402 & 0.000 & 0.012 & 0.000 & 0.102 & A32-A33 & & 0.265 & & & & \\
\hline A $11-A 12$ & 0.160 & 0.001 & 0.000 & 0.540 & 0.000 & 0.001 & A33-A34 & & 0.133 & & & & \\
\hline A12-A13 & 0.269 & 0.000 & 0.001 & 0.147 & 0.000 & 0.002 & A34-A35 & & 0.006 & & & & \\
\hline A13-A14 & 0.650 & 0.000 & 0.000 & 0.411 & 0.032 & 0.083 & A35-A36 & & 0.004 & & & & \\
\hline A14-A15 & 0.828 & 0.000 & 0.013 & 0.462 & 0.010 & 0.159 & A36-A37 & & 0.000 & & & & \\
\hline A15-A16 & 0.427 & 0.000 & 0.015 & 0.807 & 0.000 & 0.170 & A37-A38 & & 0.000 & & & & \\
\hline A16-A17 & 0.854 & 0.052 & 0.000 & 0.505 & 0.001 & 0.279 & A38-A39 & & 0.162 & & & & \\
\hline A17-A18 & 0.001 & 0.052 & 0.000 & 0.978 & 0.004 & 0.618 & A39-A40 & & 0.007 & & & & \\
\hline A18-A19 & 0.195 & 0.000 & 0.599 & 0.868 & 0.273 & 0.032 & A40-A41 & & 0.532 & & & & \\
\hline A19-A20 & 0.709 & 0.163 & 0.003 & 0.958 & 0.216 & 0.278 & A41-A42 & & 0.030 & & & & \\
\hline A $20-A 21$ & 0.022 & 0.096 & 0.000 & 0.000 & 0.000 & 0.901 & A42-A43 & & 0.064 & & & & \\
\hline A21-A22 & 0.000 & 0.164 & 0.000 & 0.030 & 0.151 & 0.701 & & & & & & & \\
\hline
\end{tabular}
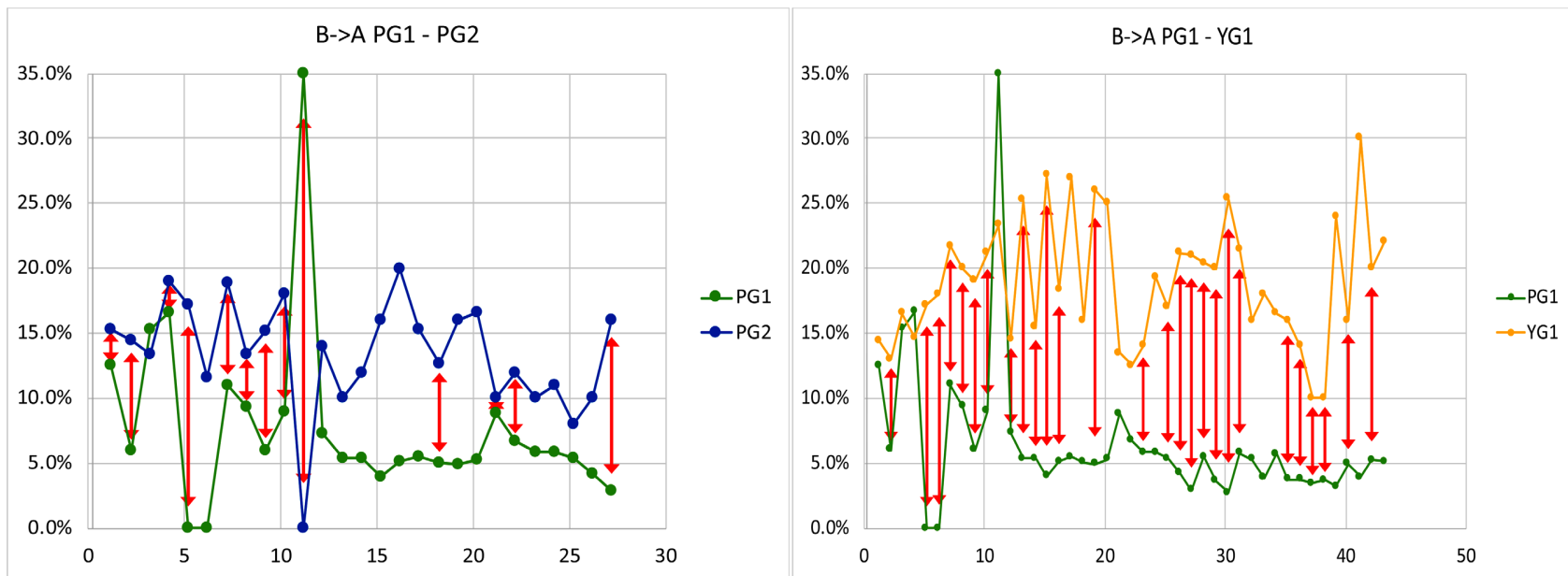


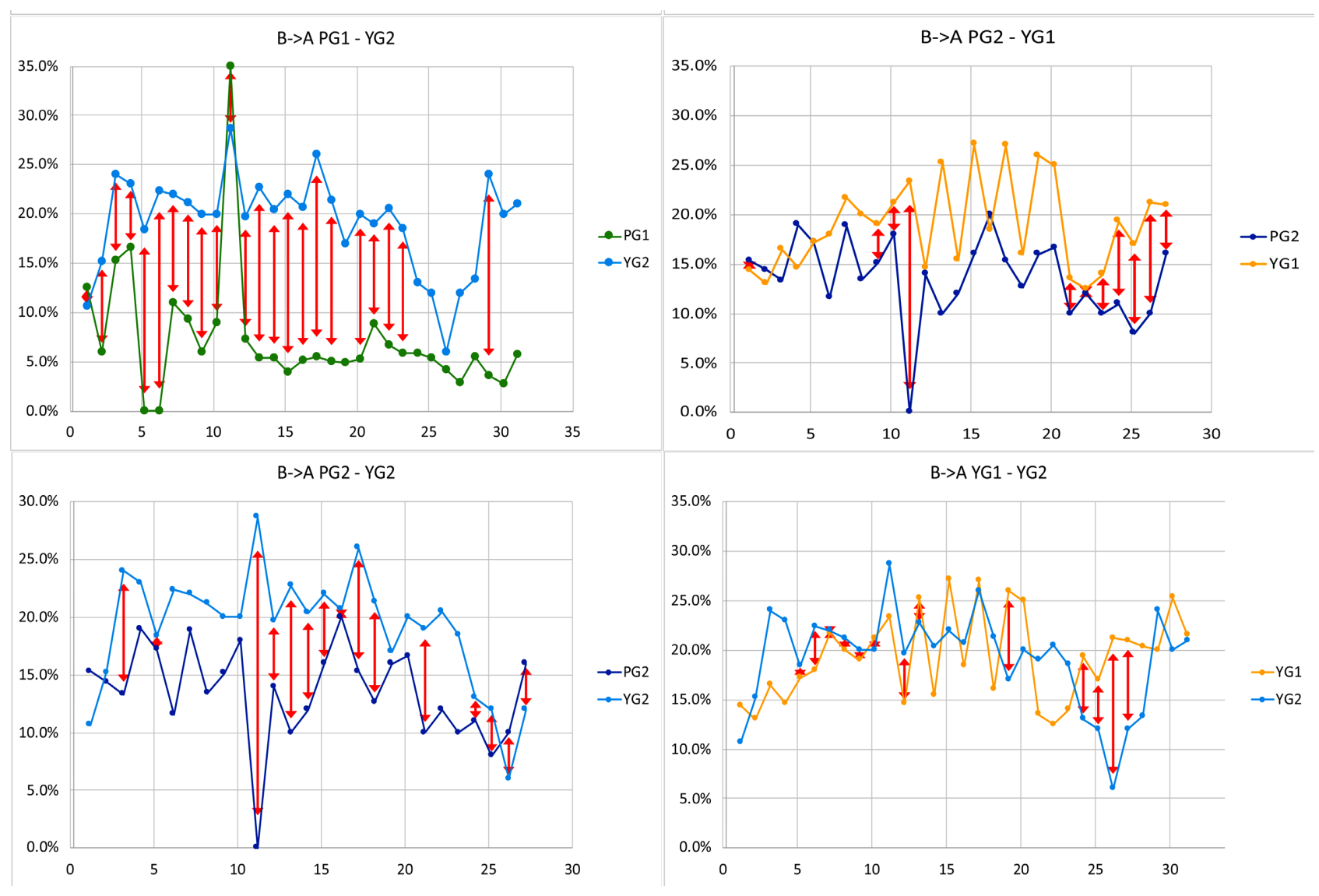

Figure 7. Comparison of the choice transition from the " $\mathrm{B}$ " to the " $\mathrm{A}$ " picture for the corresponding sessions of each group pair. The red arrows indicate where the transitions $\mathrm{B} \rightarrow \mathrm{A}$ are statistically different (Mann-Whitney $p<0.05$ ) between the two groups.

Table 7. Tally of the statistically significant differences for the choice transition from the " $A$ " to the "B" picture for the corresponding sessions of each group pair. We compared the maximum number of common sessions for each pair of groups via a Mann-Whitney test, and we report the number of sessions for which $p<0.05$.

\begin{tabular}{llll}
\hline Comparison & N tran & N sig & $\%$ diff \\
PG1-PG2 & 27 & 10 & $37 \%$ \\
PG1-YG1 & 43 & 32 & $74 \%$ \\
PG1-YG2 & 31 & 22 & $71 \%$ \\
PG2-YG1 & 27 & 14 & $52 \%$ \\
PG2-YG2 & 27 & 10 & $37 \%$ \\
YG1-YG2 & 31 & 11 & $35 \%$ \\
\hline
\end{tabular}

distribution indicates a "trend" or, in any case, a deviation from pure casuality. We measure this non-casuality via a Mann-Whitney test of the frequencies of A $\rightarrow \mathrm{B}$ vs. $\mathrm{B} \rightarrow \mathrm{A}$ transitions for each group session. Table 9 shows the differences for each group between transitions, but this is no statistics between groups. The number of statistically different transitions is 4 in 43 for PG1 (9\%), 3 in 27 for PG2 (11\%), 4 in 43 for YG1 (9\%), and 2 in 31 for YG2 2 (6\%). 
Table 8. Tally of the statistically significant differences for the choice transition from the "B" to the "A" picture for the corresponding sessions of each group pair. We compared the maximum number of common sessions for each pair of groups via a Mann-Whitney test, and we report the number of sessions for which $p<0.05$.

\begin{tabular}{cccc}
\hline Comparison & N tran & N sig & \% diff \\
\hline PG1-PG2 & 27 & 13 & $48 \%$ \\
PG1-YG1 & 43 & 27 & $62 \%$ \\
PG1-YG2 & 31 & 23 & $74 \%$ \\
PG2-YG1 & 27 & 11 & $40 \%$ \\
PG2-YG2 & 27 & 15 & $55 \%$ \\
YG1-YG2 & 31 & 12 & $39 \%$ \\
\hline
\end{tabular}

Table 9. Comparison of each group's A $\rightarrow$ B vs. B $\rightarrow$ A transition frequency. The value reported is the Mann-Whitney statistics probability. The cells in red show statistical differences $(p<0.05)$.

\begin{tabular}{|c|c|c|c|c|c|c|c|c|c|}
\hline \multicolumn{10}{|c|}{ Comparison non-casuality } \\
\hline Session & PG1 & PG2 & YG1 & YG2 & Session & PG1 & PG2 & YG1 & YG2 \\
\hline A00-A01 & 0.90 & 0.51 & 0.64 & 0.01 & A22-A23 & 0.29 & 0.15 & 0.45 & 0.19 \\
\hline A01-A02 & 0.50 & 0.22 & 0.59 & 0.22 & A23-A24 & 0.51 & 0.23 & 0.60 & 0.12 \\
\hline $\mathrm{A} 02-\mathrm{A} 03$ & 0.87 & 0.25 & 0.41 & 0.41 & A24-A25 & 0.64 & 0.03 & 0.15 & 0.99 \\
\hline A03-A04 & 0.33 & 0.48 & 0.81 & 0.93 & A25-A26 & 0.37 & 0.79 & 0.94 & 0.79 \\
\hline A04-A05 & 0.83 & 0.54 & 0.54 & 0.33 & A26-A27 & 0.36 & 0.42 & 0.98 & 0.29 \\
\hline A05-A06 & 1.00 & 0.02 & 0.55 & 0.70 & A27-A28 & 0.41 & & 0.39 & 0.04 \\
\hline A06-A07 & 0.76 & 0.13 & 0.34 & 0.57 & A28-A29 & 0.36 & & 0.72 & 0.16 \\
\hline A07-A08 & 0.12 & 0.17 & 0.66 & 0.96 & A29-A30 & 0.31 & & 0.13 & 0.30 \\
\hline A08-A09 & 0.79 & 0.67 & 0.91 & 0.88 & A $30-A 31$ & 0.36 & & 0.84 & 0.42 \\
\hline A09-A10 & 0.00 & 0.20 & 0.68 & 0.10 & $\mathrm{~A} 31-\mathrm{A} 32$ & 0.15 & & 0.50 & \\
\hline A10-A11 & 0.00 & 1.00 & 0.88 & 0.19 & A32-A33 & 0.64 & & 0.49 & \\
\hline $\mathrm{A} 11-\mathrm{A} 12$ & 0.88 & 0.78 & 0.55 & 0.76 & A33-A34 & 0.25 & & 0.88 & \\
\hline A12-A13 & 0.63 & 0.97 & 0.48 & 0.90 & A34-A35 & 0.21 & & 0.37 & \\
\hline $\mathrm{A} 13-\mathrm{A} 14$ & 0.64 & 0.45 & 0.61 & 0.50 & A35-A36 & 0.56 & & 0.83 & \\
\hline A14-A15 & 0.91 & 0.31 & 0.71 & 0.63 & A36-A37 & 0.33 & & 0.99 & \\
\hline A15-A16 & 0.33 & 0.45 & 0.89 & 0.69 & A37-A38 & 0.27 & & 0.83 & \\
\hline A16-A17 & 0.22 & 0.42 & 0.01 & 0.44 & A38-A39 & 0.28 & & 0.11 & \\
\hline A17-A18 & 0.45 & 0.76 & 0.00 & 0.74 & A39-A40 & 0.15 & & 0.25 & \\
\hline A18-A19 & 0.16 & 0.74 & 0.51 & 0.46 & A40-A41 & 0.14 & & 0.04 & \\
\hline $\mathrm{A} 19-\mathrm{A} 20$ & 0.55 & 0.61 & 0.01 & 0.60 & $\mathrm{~A} 41-\mathrm{A} 42$ & 0.14 & & 0.35 & \\
\hline $\mathrm{A} 20-\mathrm{A} 21$ & 0.30 & 0.09 & 0.39 & 0.72 & A42-A43 & 0.10 & & 0.97 & \\
\hline A $21-A 22$ & 0.18 & 0.19 & 0.15 & 0.63 & & & & & \\
\hline
\end{tabular}




\subsection{Comparison of the Groups through the Evolution of "Flux" and "Focus"}

Using the frequencies of transitions $\mathrm{A} \rightarrow \mathrm{B}$ and $\mathrm{B} \rightarrow \mathrm{A}$, we construct two derived quantities. We call "flux" the sum of changes $A \rightarrow B$ and $B \rightarrow A$ as it indicates the group activity between sessions, while we call "focus" the difference of transitions $\mathrm{B} \rightarrow \mathrm{A}$ minus $\mathrm{A} \rightarrow \mathrm{B}$, as it indicates the net tendency toward (if positive) or away from (if negative) the initial choice of pictures.

We have compared the flux and focus frequencies for each transition between each pair of the four groups via Mann-Whitney tests.

Table 10 and Figure 8 present the comparison of the frequency of the sum of

Table 10. Comparison of the sum of choice transitions from the " $\mathrm{A}$ " to the "B" plus those from the "B" to the "A" picture (flux) for the same sessions in the different groups. The value reported is the Mann-Whitney statistics probability. The cells in red show statistical differences $(p<0.05)$.

\begin{tabular}{|c|c|c|c|c|c|c|c|c|c|c|c|c|c|}
\hline \multicolumn{14}{|c|}{ Flux } \\
\hline Session & $\begin{array}{c}\text { PG1- } \\
\text { PG2 }\end{array}$ & $\begin{array}{l}\text { PG1- } \\
\text { YG1 }\end{array}$ & $\begin{array}{l}\text { PG1- } \\
\text { YG2 }\end{array}$ & $\begin{array}{l}\text { PG2- } \\
\text { YG1 }\end{array}$ & $\begin{array}{l}\text { PG2- } \\
\text { YG2 }\end{array}$ & $\begin{array}{l}\text { YG1- } \\
\text { YG2 }\end{array}$ & Session & $\begin{array}{c}\text { PG1- } \\
\text { PG2 }\end{array}$ & $\begin{array}{l}\text { PG1- } \\
\text { YG1 }\end{array}$ & $\begin{array}{l}\text { PG1- } \\
\text { YG2 }\end{array}$ & $\begin{array}{l}\text { PG2- } \\
\text { YG1 }\end{array}$ & $\begin{array}{l}\text { PG2- } \\
\text { YG2 }\end{array}$ & $\begin{array}{l}\text { YG1- } \\
\text { YG2 }\end{array}$ \\
\hline A00-A01 & 0.075 & 0.347 & 0.354 & 0.203 & 0.325 & 0.797 & A22-A23 & 0.938 & 0.000 & 0.000 & 0.148 & 0.211 & 0.841 \\
\hline A01-A02 & 0.000 & 0.000 & 0.000 & 0.144 & 0.045 & 0.451 & A23-A24 & 0.543 & 0.000 & 0.259 & 0.135 & 0.244 & 0.881 \\
\hline A02-A03 & 0.592 & 0.310 & 0.001 & 0.338 & 0.000 & 0.000 & A24-A25 & 0.001 & 0.000 & 0.000 & 0.005 & 0.375 & 0.000 \\
\hline A03-A04 & 0.967 & 0.963 & 0.167 & 0.287 & 0.248 & 0.018 & A25-A26 & 0.352 & 0.000 & 0.000 & 0.000 & 0.003 & 0.000 \\
\hline A04-A05 & 0.000 & 0.000 & 0.000 & 0.440 & 0.124 & 0.403 & A26-A27 & 0.002 & 0.000 & 0.294 & 0.000 & 0.824 & 0.000 \\
\hline A05-A06 & 0.000 & 0.000 & 0.000 & 0.006 & 0.000 & 0.146 & A27-A28 & & 0.000 & 0.000 & & & 0.230 \\
\hline A06-A07 & 0.000 & 0.000 & 0.000 & 0.070 & 0.011 & 0.087 & A28-A29 & & 0.000 & 0.000 & & & 0.153 \\
\hline A07-A08 & 0.000 & 0.000 & 0.000 & 0.039 & 0.026 & 0.815 & A29-A30 & & 0.000 & 0.000 & & & 0.602 \\
\hline A08-A09 & 0.000 & 0.000 & 0.000 & 0.000 & 0.034 & 0.451 & $\mathrm{~A} 30-\mathrm{A} 31$ & & 0.000 & 0.010 & & & 0.524 \\
\hline A09-A10 & 0.030 & 0.664 & 0.381 & 0.008 & 0.000 & 0.148 & A31-A32 & & 0.000 & & & & \\
\hline A10-A11 & 0.000 & 0.521 & 0.395 & 0.000 & 0.000 & 0.828 & A $32-A 33$ & & 0.000 & & & & \\
\hline A11-A12 & 0.946 & 0.000 & 0.000 & 0.000 & 0.000 & 0.010 & A33-A34 & & 0.000 & & & & \\
\hline A12-A13 & 0.418 & 0.000 & 0.000 & 0.000 & 0.000 & 0.975 & A34-A35 & & 0.000 & & & & \\
\hline A13-A14 & 0.272 & 0.000 & 0.000 & 0.000 & 0.000 & 0.005 & A $35-A 36$ & & 0.006 & & & & \\
\hline A14-A15 & 0.002 & 0.000 & 0.000 & 0.000 & 0.005 & 0.003 & A36-A37 & & 0.000 & & & & \\
\hline A $15-A 16$ & 0.674 & 0.000 & 0.000 & 0.904 & 0.860 & 0.177 & A37-A38 & & 0.000 & & & & \\
\hline A16-A17 & 0.000 & 0.005 & 0.000 & 0.129 & 0.008 & 0.442 & A38-A39 & & 0.088 & & & & \\
\hline A17-A18 & 0.049 & 0.000 & 0.000 & 0.003 & 0.028 & 0.378 & A39-A40 & & 0.548 & & & & \\
\hline A18-A19 & 0.000 & 0.000 & 0.536 & 0.002 & 0.945 & 0.004 & A40-A41 & & 0.616 & & & & \\
\hline A19-A20 & 0.000 & 0.079 & 0.000 & 0.604 & 0.278 & 0.208 & A41-A42 & & 0.842 & & & & \\
\hline A20-A21 & 0.002 & 0.000 & 0.000 & 0.031 & 0.007 & 0.111 & A $42-A 43$ & & 0.711 & & & & \\
\hline $\mathrm{A} 21-\mathrm{A} 22$ & 0.930 & 0.000 & 0.000 & 0.039 & 0.001 & 0.199 & & & & & & & \\
\hline
\end{tabular}



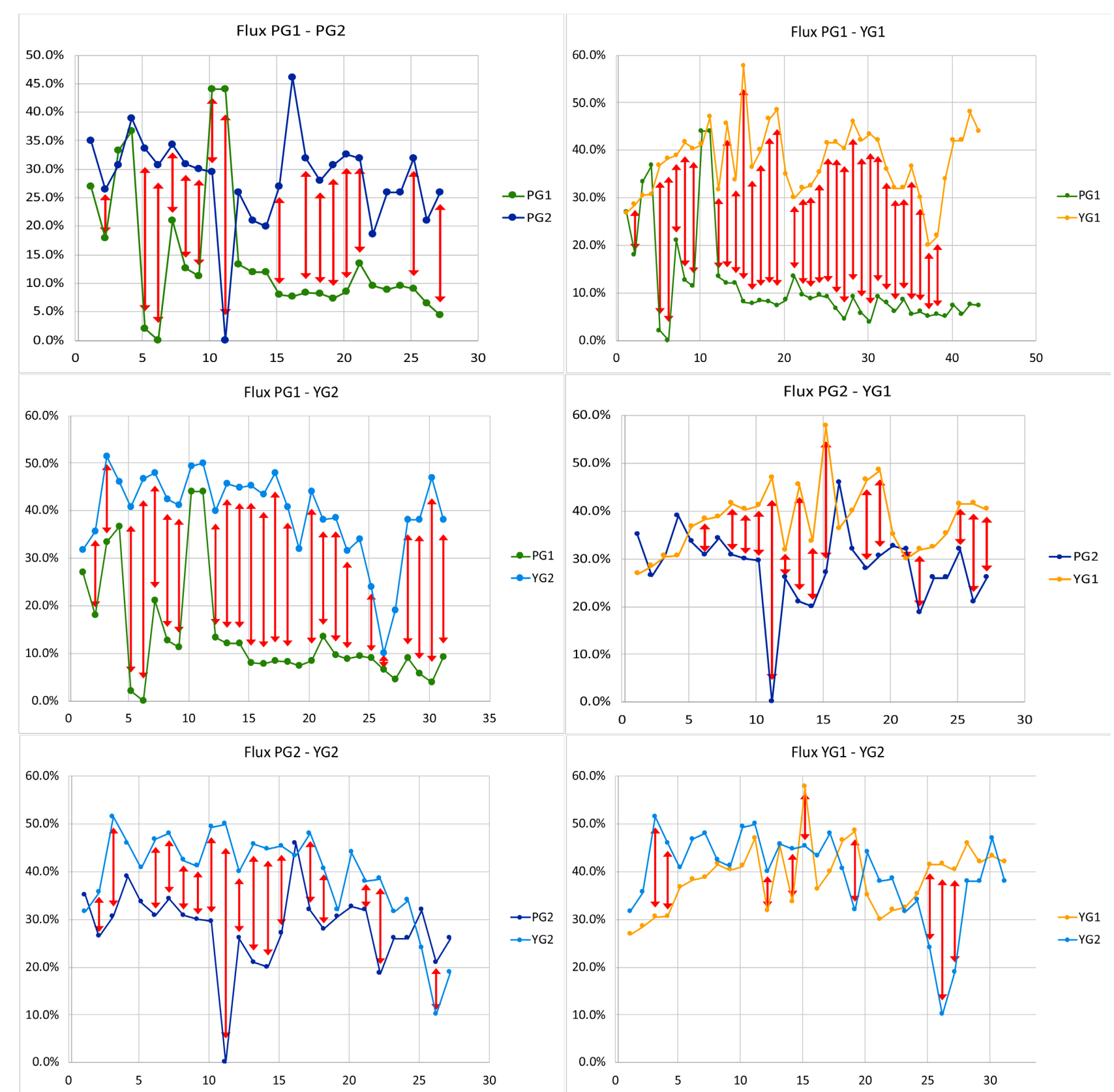

Figure 8. Comparison of the sum of choice transition frequencies from the " $A$ " to the " $B$ " picture plus those from the " $B$ " to the " $A$ " picture (flux) for the same sessions in the different groups. The red arrows indicate where the transitions $A \rightarrow B+B \rightarrow A$ are statistically different (Mann-Whitney $p<0.05)$ between the two groups.

choice transitions from the " $\mathrm{A}$ " to the "B" plus those from the "B" to the " $\mathrm{A}$ " picture (focus) for the same sessions in the different groups.

Table 11 presents the significative differences between the groups for the flux, i.e., the changes of choice indicator $\mathrm{A} \rightarrow \mathrm{B}+\mathrm{B} \rightarrow \mathrm{A}$ that gives us the total amount of changes. We observe a similar trend to the choice of $A$ and $A \rightarrow B$ concerning the age group as the smallest number of significant differences is in YG1 vs. YG2 (26\%) and PG1 vs. PG2 (59\%); Considering the same "familial frame" for the two groups, the differences between parent and adolescents are $74 \%$ for PG1 vs. 
YG1 and 63\% for PG2 vs. YG2. The significant differences between parents and adolescents in different "familial frames" are 77\% for PG1 vs. YG2 and 59\% for PG2 vs. YG1.

Table 12 and Figure 9 show the comparison between groups for the focus,

Table 11. Tally of the statistically significant differences for the sum of choice transitions from the " $A$ " to the " $\mathrm{B}$ " picture plus those from the " $\mathrm{B}$ " to the " $\mathrm{A}$ " picture (flux) for the same sessions in the different groups. We compared the maximum number of common sessions for each pair of groups via a Mann-Whitney test, and we report the number of sessions for which $p<0.05$.

\begin{tabular}{cccc}
\hline Comparison & N tran & N sig & \% diff \\
\hline PG1-PG2 & 27 & 16 & $59 \%$ \\
PG1-YG1 & 43 & 32 & $74 \%$ \\
PG1-YG2 & 31 & 24 & $77 \%$ \\
PG2-YG1 & 27 & 16 & $59 \%$ \\
PG2-YG2 & 27 & 17 & $63 \%$ \\
YG1-YG2 & 31 & 8 & $26 \%$ \\
\hline
\end{tabular}

Table 12. Comparison of the difference of choice transitions from the " $B$ " to the " $A$ " minus those from the " $A$ " to the " $B$ " picture (focus) for the same sessions in the different groups. The value reported is the Mann-Whitney statistics probability. The cells in red show statistical differences $(\mathrm{p}<0.05)$.

\begin{tabular}{|c|c|c|c|c|c|c|c|c|c|c|c|c|c|}
\hline \multicolumn{14}{|c|}{ Focus } \\
\hline Session & $\begin{array}{l}\text { PG1- } \\
\text { PG2 }\end{array}$ & $\begin{array}{l}\text { PG1- } \\
\text { YG1 }\end{array}$ & $\begin{array}{l}\text { PG1- } \\
\text { YG2 }\end{array}$ & $\begin{array}{l}\text { PG2- } \\
\text { YG1 }\end{array}$ & $\begin{array}{l}\text { PG2- } \\
\text { YG2 }\end{array}$ & $\begin{array}{l}\text { YG1- } \\
\text { YG2 }\end{array}$ & Session & $\begin{array}{c}\text { PG1- } \\
\text { PG2 }\end{array}$ & $\begin{array}{l}\text { PG1- } \\
\text { YG1 }\end{array}$ & $\begin{array}{l}\text { PG1- } \\
\text { YG2 }\end{array}$ & $\begin{array}{l}\text { PG2- } \\
\text { YG1 }\end{array}$ & $\begin{array}{l}\text { PG2- } \\
\text { YG2 }\end{array}$ & $\begin{array}{l}\text { YG1- } \\
\text { YG2 }\end{array}$ \\
\hline A00-A01 & 0.470 & 0.645 & 0.029 & 0.218 & 0.088 & 0.024 & A $22-A 23$ & 0.132 & 0.175 & 0.193 & 0.744 & 0.064 & 0.064 \\
\hline A01-A02 & 0.030 & 0.915 & 0.719 & 0.324 & 0.152 & 0.730 & A23-A24 & 0.238 & 0.747 & 0.145 & 0.211 & 0.632 & 0.125 \\
\hline A02-A03 & 0.893 & 0.503 & 0.801 & 0.252 & 0.714 & 0.235 & A24-A25 & 0.099 & 0.044 & 0.787 & 0.924 & 0.123 & 0.117 \\
\hline A03-A04 & 0.277 & 0.076 & 0.313 & 0.943 & 0.986 & 0.960 & A25-A26 & 0.400 & 0.790 & 0.410 & 0.663 & 0.661 & 0.984 \\
\hline A04-A05 & 0.997 & 0.705 & 0.452 & 0.670 & 0.385 & 0.720 & A26-A27 & 0.422 & 0.780 & 0.830 & 0.774 & 0.884 & 0.546 \\
\hline A05-A06 & 0.028 & 0.333 & 0.319 & 0.446 & 0.440 & 0.992 & A $27-A 28$ & & 0.225 & 0.037 & & & 0.390 \\
\hline A06-A07 & 0.511 & 0.493 & 0.464 & 0.992 & 0.165 & 0.152 & A28-A29 & & 0.378 & 0.489 & & & 0.105 \\
\hline A07-A08 & 0.012 & 0.131 & 0.314 & 0.662 & 0.203 & 0.587 & A29-A30 & & 0.131 & 0.121 & & & 0.073 \\
\hline A08-A09 & 0.977 & 0.575 & 0.644 & 0.840 & 0.567 & 0.877 & A $30-A 31$ & & 0.879 & 0.840 & & & 0.743 \\
\hline A09-A10 & 0.000 & 0.000 & 0.066 & 0.436 & 0.020 & 0.127 & A31-A32 & & 0.254 & & & & \\
\hline A10-A11 & 0.000 & 0.004 & 0.061 & 0.697 & 0.235 & 0.347 & A32-A33 & & 0.753 & & & & \\
\hline A11-A12 & 0.833 & 0.662 & 0.882 & 0.651 & 0.741 & 0.764 & A33-A34 & & 0.348 & & & & \\
\hline A12-A13 & 0.502 & 0.206 & 0.862 & 0.402 & 0.896 & 0.424 & A34-A35 & & 0.108 & & & & \\
\hline A13-A14 & 0.245 & 0.699 & 0.699 & 0.235 & 0.257 & 0.771 & A35-A36 & & 0.418 & & & & \\
\hline A14-A15 & 0.333 & 0.358 & 0.913 & 0.160 & 0.333 & 0.867 & A $36-A 37$ & & 0.243 & & & & \\
\hline A15-A16 & 0.317 & 0.945 & 0.486 & 0.462 & 0.734 & 0.590 & A37-A38 & & 0.143 & & & & \\
\hline
\end{tabular}




\section{Continued}

\begin{tabular}{lllllllll}
\hline A16-A17 & 0.349 & 0.078 & 0.652 & 0.031 & 0.444 & 0.237 & A38-A39 & 0.942 \\
A17-A18 & 0.355 & 0.000 & 0.795 & 0.085 & 0.462 & 0.048 & A39-A40 & 0.087 \\
A18-A19 & 0.992 & 0.878 & 0.694 & 0.910 & 0.824 & 0.916 & A40-A41 & 0.639 \\
A19-A20 & 0.513 & 0.021 & 0.636 & 0.043 & 0.977 & 0.008 & A41-A42 & 0.151 \\
A20-A21 & 0.156 & 0.219 & 0.774 & 0.720 & 0.334 & 0.630 & A42-A43 & 0.373 \\
A21-A22 & 0.438 & 0.023 & 0.716 & 0.022 & 0.652 & 0.092 & & \\
\hline
\end{tabular}
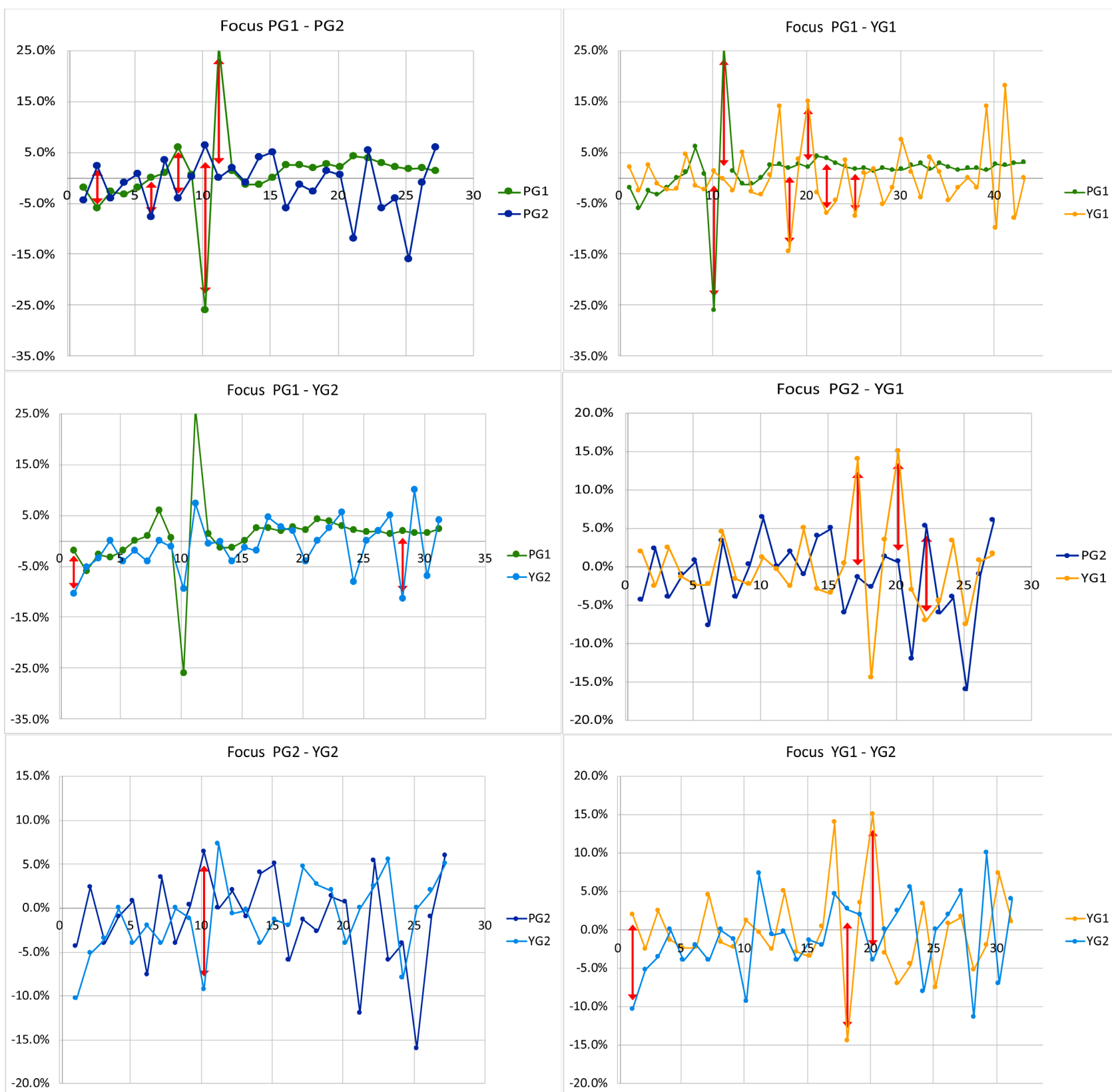

Figure 9. Comparison of the difference of choice transitions from the "B" to the "A" minus those from the "A" to the "B" picture (focus) for the same sessions in the different groups. The red arrows indicate where the transitions $\mathrm{B} \rightarrow \mathrm{A}-\mathrm{A} \rightarrow \mathrm{B}$ are statistically different (Mann-Whitney $p<0.05)$ between the two groups. 
Table 13. Tally of the statistically significant differences for the difference of choice transitions from the " $\mathrm{B}$ " to the " $\mathrm{A}$ " picture minus those from the " $\mathrm{A}$ " to the " $\mathrm{B}$ " picture (focus) for the same sessions in the different groups. We compared the maximum number of common sessions for each pair of groups via a Mann-Whitney test, and we report the number of sessions for which $p<0.05$.

\begin{tabular}{cccc}
\hline Comparison & N tran & N sig & \% diff \\
\hline PG1-PG2 & 27 & 4 & $15 \%$ \\
PG1-YG1 & 43 & 6 & $14 \%$ \\
PG1-YG2 & 31 & 2 & $6 \%$ \\
PG2-YG1 & 27 & 3 & $11 \%$ \\
PG2-YG2 & 27 & 1 & $4 \%$ \\
YG1-YG2 & 31 & 3 & $10 \%$ \\
\hline
\end{tabular}

i.e., the difference in the frequency of change of choices $\mathrm{B} \rightarrow \mathrm{A}-\mathrm{A} \rightarrow \mathrm{B}$ expressing the trend toward (if positive) or away from (if negative) the initial selection in questionnaire 0 .

Table 13 shows the number of significant differences between groups in the indicator $\mathrm{A} \rightarrow \mathrm{B}-\mathrm{B} \rightarrow \mathrm{A}$. We observe a trend different from $\mathrm{A}, \mathrm{A} \rightarrow \mathrm{B}, \mathrm{B} \rightarrow \mathrm{A}$, and flux with the minimum of statistical differences in PG2 vs. YG2, then PG1 vs. PG2, YG1 vs. YG2, PG2 vs. YG1, PG1 vs. YG1, and finally PG1 vs. PG2.

\section{Discussion}

As is the case in quantum mechanics, the problem of measurement is also central in psychophysics. The unconscious is, by definition, unknowledgeable, and not only because it is "unconscious" but also because the "detector" is the cognitive part of the individual, which is deeply influenced by, and indeed built upon, the unconscious itself. Given the presence of several potentially connected individuals, we have made the hypothesis that the entanglement effects could be more pronounced in the case of a group setting. We believe that the amplification of the unconscious via group dynamics is the best way to observe it. In quantum physics, a microscopic process is "amplified" by the "observer" at the macroscopic level, allowing the measurement. Only after the amplification, we can observe a microscopic quantum process as a physical phenomenon with an act of measurement. The irreversibility of such an act is still an open argument of discussion.

This article analyzes the differences between the groups attending the DBT training. In our previous publication (Fernandez-Rivas et al., 2021b, 2021a), we noticed that the answers to the questionnaire zero, administered before the training, are very polarized, which is similar to what we remarked in a previous study of DBT closed groups (Fernandez-Rivas et al., 2020).

We begin discussing the evolutions of the A's answers. These are different in the four groups. At the end of the training, the parent groups PG1 and PG2 show an increase in the choice of the initially preferred image $(+4.1 \%$ and 
$+11.5 \%)$ while the adolescent groups YG1 and YG2 present a diminution $(-11.7 \%$ and $-5.6 \%)$. In a previous experiment on closed groups (FernandezRivas et al., 2020), we observed a decrease to 73\% (PG1), a growth to 80\% (PG2), a reduction to $62 \%$ (YG1), and $56 \%$ (YG2).

From these results, it seems possible to conclude that A's pictures' evolution depends more on the age group (parents or adolescents) than on the therapy setting.

We now turn our attention to the changes between $\mathrm{A}$ and $\mathrm{B}$ answers. The two adolescent groups show relatively few statistical differences in the $\mathrm{A} \rightarrow \mathrm{B}$ and $\mathrm{B} \rightarrow$ A transitions during the therapy. The groups of parents present, with a similar trend, few differences in $\mathrm{A} \rightarrow \mathrm{B}$ but more differences in $\mathrm{B} \rightarrow \mathrm{A}$. The differences between parents and adolescents in $\mathrm{A} \rightarrow \mathrm{B}$ and $\mathrm{B} \rightarrow \mathrm{A}$ transitions are more frequent than within parent and adolescent groups throughout the training without a clear time pattern.

The pattern of the flux (sum of $\mathrm{A} \rightarrow \mathrm{B}$ and $\mathrm{B} \rightarrow \mathrm{A}$ transitions) is similar to the A's choice and the $\mathrm{A} \rightarrow \mathrm{B}$ transitions. There are few differences between the two parent groups and the two adolescent ones, and the generational status produces similar answers and a similar trend throughout the therapy.

The focus (difference between $\mathrm{B} \rightarrow \mathrm{A}-\mathrm{A} \rightarrow \mathrm{B}$ transitions) measures the tendency to revert to the initial choice of pictures before the training begins $\left(0^{\text {th }}\right.$ questionnaire). We remark very few differences between the groups, generational, in the same therapy and crossed therapy, without the previously noticed lowest rate of significant changes between the two parent and two adolescent groups.

Lastly, we observe that the non-casuality (significant difference between $\mathrm{A} \rightarrow \mathrm{B}$ and $\mathrm{B} \rightarrow \mathrm{A}$ transitions)shows few differences in the longitudinal analysis for all the groups (Fernandez-Rivas et al., 2020, 2021a, 2021b; Trojaola-Zapirain et al., 2014, 2015, 2016, 2019).

We try now to interpret the results obtained. As previously reported (FernandezRivas et al., 2021b, 2021a), participants in slow-open groups probably experience the influence of the environment more directly than in closed groups, with strong clanic loyalties eventually prevailing on the group continuum. The group therapy could help the individuation (in the Jungian sense), attenuating the clanic loyalties in favor of the group continuum. For this reason, the therapeutical work could create deep anxiety that the slow-open group setting, milder than the closed group one, could help attenuate. We consider the high initial "orientation" (A's choices before the group's socio-cultural effect. The group experience ("group continuum") tends to reduce this polarization introducing a "group identity" drifting away from the external environment. However, this is a transitory phenomenon, and clanic loyalties recover and, in the parent groups, even exceed the initial orientation during the training. In other words, participants of slow-open groups experience the interaction with the external environment, producing strong clan loyalties and resulting in a high "orientation" 
(A's choices before the constitution of the group largely more than 50\%) that is "recovered" (and in a group even exceeded) during the sessions. We suppose that the slow-open group promotes a "clan continuum" primarily influenced by generational conditions and external environments.

As discussed in (Fernandez-Rivas et al., 2021b, 2021a), the interpretation of the return to the initial A's choice is not evident. Therefore, we propose considering the initially preferred answer (A answer of the $0^{\text {th }}$ questionnaire) as the "personal" answer independent of the group's influence. Then we can interpret the reverting to the initial selections as a reaction to the "group continuum" and in the direction of the familiar and social environment that we can indicate as "normal clanity". This behavior is consistent with the "canonical" group evolution: the participants mourn the end of the group, and they tend to return to their normal clanity to preserve themselves from the group's demise.

We can interpret the relatively few differences in YG1 vs. YG2 as adolescents experiencing the feeling of belonging to a "society in the society". The same clanic loyalty of another kind of "society in the society" is also present in PG1 vs. PG2. The generational state orients the choices with a very similar trend in groups of parents and adolescents, probably because the influence of life experience and existential evolution are similar

\section{Conclusion}

This experiment was conducted in 2017-2019 during a Dialectical Behavior Therapy skills training at the Psychiatric Service of the Basurto University Hospital in Bilbao, Spain. Seven publications have reported the results of similar experiments (Fernandez-Rivas et al., 2020, 2021a, 2021b; Trojaola-Zapirain et al., 2014, 2015, 2016, 2019). This series of works points to the existence of a "group unconscious" operating according to the "basic assumptions" postulated by W. Bion. According to him, the psyches of the individuals participating in a group immediately bond together into a group psychical entity that evolves during the group's existence. Bion has coined the term "valency" for this effect, more akin to a tropism than to a goal-directed attitude. The group setting enhances this effect since, according to Bion, groups "amplify emotional reactions, resulting in a combustible process of emotional contagion" (Bion, 1961).

Several authors have observed that it is hitherto impossible to measure the unconscious directly (Atmanspacher, 2004; Cerf \& Adami, 1997, 1998). To avoid this difficulty, we have elaborated a protocol for an "indirect measure" via our "absurd questionnaire" in a group setting. With this experiment, we want to see whether a mental state, the hypothesized entanglement of the individuals' minds in a group setting, can have material effects, such as the answers provided to our questionnaire.

In recent papers (Fernandez-Rivas et al., 2021a, 2021b), we find a more significant social and generational environment influence than in the previous setting (slow open group versus closed group).In addition, it seems that clanic loyalty 
influences the group continuum more than in the previously studied closed groups.

Moreover, particularly for adolescents, the feeling of identity loss introduced by the "group continuum" could bring stress and anxiety and ultimately provoke the exit from the group when the "focus" onto A's choices is lowest, and the entanglement is highest. The parents react with a marked return to the preferred answer chosen before the beginning of the therapy. Psychoanalytically, we would call this a resistance to change, but we can also consider this attitude as typical mourning of therapy.

Suppose we regard the eventual return to the preferred image as an expression of clanic loyalties. In that case, these clanic loyalties, very apparent for adolescents in dress code and above all body look when moving from the family to the friend's envelope, are even more present in parents, albeit with a more hidden, less open, attitude.

The group continuum originates from the entanglement of individual psyches forming a group entity endowed with its own identity. This "loss of clanity" may create an intense discomfort and lead to a flight from the group situation (group continuum and entanglement), either leaving the therapy altogether or, more discretely, reverting to the choices of the $0^{\text {th }}$ questionnaire.

We can suppose that this entanglement is weaker in slow-open groups than in closed groups. Thus, external environment influence in slow-open groups appears more significant, making the conflict between friend clan, family clan, and group continuum less acute.

The slow-open setting probably reinforces the Dialectical Behavior Group Therapy participation, allowing adolescents and parents to experience a moderated conflict with clanic preexistent loyalties and more relaxed interaction with the group continuum.

Suppose we try to give a therapeutical valence to these results. In that case, we observe that the effect of the group, while present, is strongly "opposed" by the "clanic loyalties" of the participants, possibly due to the slow-open nature of these groups. This fact may suggest that slow-open groups trainers must consider that the effect of the "environment" remains strong, and they should give special attention to the emergence of loyalty conflicts and identity loss angst during the training.

\section{Conflicts of Interest}

The authors declare no conflicts of interest regarding the publication of this paper.

\section{References}

Aspect, A., Grangier, P., \& Roger, G. (1982). Experimental Realization of Einstein-Podolsky-Rosen-Bohm Gedanken Experiment: A New Violation of Bell's Inequalities. Physical Review Letters, 49, 91-94. https://doi.org/10.1103/PhysRevLett.49.91 
Atmanspacher, H. (2004). Quantum Approaches to Consciousness. Stanford Encyclopedia of Philosophy. https://plato.stanford.edu/entries/qt-consciousness

Baaquie, B. E., \& Martin, F. (2005). Quantum Psyche-Quantum Field Theory of the Human Psyche. NeuroQuantology, 3, 7-42. https://doi.org/10.14704/nq.2005.3.1.57

Beck, F., \& Eccles, J. (1992). Quantum Aspects of Brain Activity and the Role of Consciousness. Proceedings of the National Academy of Sciences of the United States of America, 89, 11357-11361. https://doi.org/10.1073/pnas.89.23.11357

Bell, J. (1964). On the Einstein-Poldolsky-Rosen Paradox. Physics Physique Fizika, 1, 195-200. https://doi.org/10.1103/PhysicsPhysiqueFizika.1.195

Bell, J. (1966). On the Problem of Hidden Variables in Quantum Mechanics. Reviews of Modern Physics, 38, 447-452. https://doi.org/10.1103/RevModPhys.38.447

Bion, W. (1961). Experiences in Groups and Other Papers. Tavistock Publications Ltd.

Bohr, N. (1935). Can Quantum-Mechanical Description of Physical Reality be Considered Complete? Physical Review, 48, 969-702. https://doi.org/10.1103/PhysRev.48.696

Cerf, N., \& Adami, C. (1997). Quantum Mechanics of Measurement. ArXiv:Quant-Ph/ 9605002v2.

Cerf, N., \& Adami, C. (1998). What Information Theory Can Tell Us about Quantum Reality. arXiv:quant-ph/9806047v1

Conte, E., Todarello, O., Federici, A., Vitiello, F., Lopane, M., \& Khrennikov, A. (2003). A Preliminary Evidence of Quantum Like Behavior in Measurement of Mental State. arXiv:quant-ph/0307201v1

Einstein, A., Podolsky, B., \& Rosen, N. (1935). Can Quantum-Mechanical Description of Physical Reality Be Considered Complete? Physical Review, 47, 777-780. https://doi.org/10.1103/PhysRev.47.777

Fernandez-Rivas, A., Sesma-Pardo, E., Kerexeta, I., Diaz-Cosgaya, A., Vivanco, E., Carminati, F., Torres, M. A. G., Fouassier, C., Martin, F., Demongeot, J., \& Carminati, G. G. (2020). Group Therapy for Adolescents and Parents: Study of Unconscious Orientation. NeuroQuantology, 18, 70-82. https://doi.org/10.14704/nq.2020.18.7.NQ20195

Fernandez-Rivas, A., Sesma-Pardo, E., Kerexeta, I., Diaz-Cosgaya, A., Vivanco, E., Carminati, F., Torres, M. A. G., Fouassier, C., Martin, F., Demongeot, J., \& Carminati, G. G. (2021a). Erratum to "Slow Open Dialectical Behavior Group Therapy for Adolescents and Parents: Longitudinal Study of Unconscious Orientation" [Psychology 12 (2021) 756-784]. Psychology, 12, 1615-1641. https://doi.org/10.4236/psych.2021.1210100

Fernandez-Rivas, A., Sesma-Pardo, E., Kerexeta, I., Diaz-Cosgaya, A., Vivanco, E., Carminati, F., Torres, M. A. G., Fouassier, C., Martin, F., Demongeot, J., \& Carminati, G. G. (2021b). Slow Open Dialectical Behavior Group Therapy for Adolescents and Parents: Longitudinal Study of Unconscious Orientation. Psychology, 12, 756-784. https://doi.org/10.4236/psych.2021.125047

Foulkes, S. H. (1964). Therapeutic Group Analysis. International Universities Press.

Freeman, W., \& Vitiello, G. (2016). Matter and Mind Are Entangled in Two Streams of Images Guiding Behavior and Informing the Subject Through Awareness. Mind and Matter, 14, 7-24.

Galli Carminati, G., \& Carminati, F. (2006). The Mechanism of Mourning: An Anti-Entropic Mechanism. NeuroQuantology, 4, 186-197. https://doi.org/10.14704/nq.2006.4.2.97

Galli Carminati, G., \& Martin, F. (2008). Quantum Mechanics and the Psyche. Physics of Particles and Nuclei, 39, 560-577. https://doi.org/10.1134/S1063779608040047 
Galli Carminati, G., Martin, F., \& Carminati, F. (2017). A Very Simple Quantum Model of Mind and Matter. NeuroQuantology, 15, 186-199. https://doi.org/10.14704/nq.2017.15.2.1031

Grinberg-Zylberbaum, J., Delaflor, M., Attie, L., \& Goswami, A. (1994). The Einstein-Podolsky-Rosen Paradox in the Brain: The Transferred Potential. Physics Essays, 7, 422-428.

Hamer, R. M., \& Simpson, P. M. (2009). Last Observation Carried Forward Versus Mixed Models in the Analysis of Psychiatric Clinical Trials. American Journal of Psychiatry, 166, 639-641. https://doi.org/10.1176/appi.ajp.2009.09040458

Hameroff, S., \& Penrose, R. (1996). Conscious Events as Orchestrated Spacetime Selections. Journal of Consciousness Studies, 3, 36-53.

Jung, C. G. (1952). Synchronicity: An Acausal Connecting Principle. Princeton University Press. https://doi.org/10.1515/9781400839162

Jung, C. G. (1959). The Archetypes and the Collective Unconscious (2nd ed., Vol. 9). Princeton University Press.

Jung, C. G. (1960). The Structure and Dynamics of the Psyche (Nachdr.). Routledge.

Jung, C. G. (1962). Memories and Dreams, Reflections. Vintage Editions.

Jung, C. G., \& Hull, R. F. C. (1911). Symbols of Transformation: An Analysis of the Prelude to a Case of Schizophrenia. Princeton University Press.

Jung, C. G., Pauli, W., \& Meyer, C. A. (2001). Atom and Archetype: The Pauli/Jung Letters 1932-1958 (Traduction française: <i>Correspondance 1932-1958</i>, ed. Albin Michel, 2000). Princeton University Press.

Kaës, R. (2010). Le sujet, le lien et le groupe. Groupalité psychique et alliances inconscientes. Cahiers de Psychologie Clinique, 1, 13-40. https://doi.org/10.3917/cpc.034.0013

Linehan, M. (1993). Cognitive-Behavioral Treatment of Borderline Personality Disorder. Guilford Press.

Linehan, M. (2015). DBT Skills Training Manual(2nd ed.). Guilford Press.

Marshall, I. (1989). Consciousness and Bose-Einstein Condensates. New Ideas in Psychology, 7, 73-83. https://doi.org/10.1016/0732-118X(89)90038-X

Martin, F., \& Galli Carminati, G. (2009). Synchronicity, Quantum Mechanics, and Psyche. In H. Atmanspacher, \& H. Primas (Eds.), Recasting Reality: Wolfgang Pauli's Philosophical Ideas and Contemporary Science (pp. 227-243). Springer-Verlag. https://doi.org/10.1007/978-3-540-85198-1_11

Martin, F., Carminati, F., \& Galli Carminati, G. (2009). Synchronicity, Quantum Information and the Psyche. Journal of Cosmology, 3, 580-589.*

Martin, F., Carminati, F., \& Galli Carminati, G. (2010). Quantum Information, Oscillations and the Psyche. Physics of Particles and Nuclei, 41, 425-451. https://doi.org/10.1134/S1063779610030032

Martin, F., Carminati, F., \& Galli Carminati, G. (2018). Quantum Information Theory Applied to Unconscious and Consciousness. NeuroQuantology, 16, 16-33. https://doi.org/10.14704/nq.2013.11.1.628

Miller, A. L., Rathus, J. H., \& Linehan, M. (2017). Dialectical Behavior Therapy with Suicidal Adolescents. Guilford Press.

Orlov, Y. F. (1982). The Wave Logic of Consciousness: A Hypothesis. International Journal of Theoretical Physics, 21, 37-53. https://doi.org/10.1007/BF01880263

Penrose, R. (1994). Shadows of the Mind. Oxford University Press.

Penrose, R., \& Gardner, M. (1989). The Emperor's New Mind. Oxford University Press. 
https://doi.org/10.1093/oso/9780198519737.001.0001

Pitkänen, M. (2010). Quantum Mind in TGD Universe. Journal of Nonlocality, 1, 1-42. https://journals.sfu.ca/jnonlocality/index.php/jnonlocality/article/download/17/17

Richens, J. F., Selby, J. H., \& Al-Safi, S. W. (2017). Entanglement Is Necessary for Emergent Classicality in All Physical Theories. Physical Review Letters, 119, Article ID: 080503. https://doi.org/10.1103/PhysRevLett.119.080503

Sabbadini, S., \& Vitiello, G. (2019). Entanglement and Phase-Mediated Correlations in Quantum Field Theory. Application to Brain-Mind States. Applied Sciences, 9, Article No. 3203. https://doi.org/10.3390/app9153203

Schrödinger, E. (1935). Discussion of Probability Relations between Separated Systems. Mathematical Proceedings of the Cambridge Philosophical Society, 31, 555-563. https://doi.org/10.1017/S0305004100013554

Schrödinger, E. (1936). Probability Relations between Separated Systems. Mathematical Proceedings of the Cambridge Philosophical Society, 32, 446-452. https://doi.org/10.1017/S0305004100019137

Trojaola-Zapirain, B., Carminati, F., Fernandez Rivas, M. A., Gonzalez Torres, A., Gonzales de Mendivil, E., Fouassier, C., Martin, F., Demongeot, J., \& Galli Carminati, G. (2019). An Update and Generalization of Group Unconscious Orientation in OMIE Group Training for Therapists. NeuroQuantology, 17, 14-30. https://doi.org/10.14704/nq.2019.17.1.1918

Trojaola-Zapirain, B., Carminati, F., Gonzalez Torres, A., Gonzales de Mendivil, E., Fouassier, C., Gex-Fabry, M., Martin, F., Labarere, J., Demongeot, J., Lorincz, E. N., \& Galli Carminati, G. (2014). Group Unconscious Common Orientation: Exploratory Study at the Basque Foundation for the Investigation of Mental Health Group Training for Therapists. NeuroQuantology, 12, 139-150. https://doi.org/10.14704/nq.2014.12.1.709

Trojaola-Zapirain, B., Carminati, F., Gonzalez Torres, A., Gonzales de Mendivil, E., Fouassier, C., Gex-Fabry, M., Martin, F., Labarere, J., Demongeot, J., Lorincz, E. N., \& Galli Carminati, G. (2015). Addendum on Entropy to the Exploratory Study on Group Unconscious at the Basque Foundation for the Investigation of Mental Health Group Training for Therapists. NeuroQuantology, 13, 49-56.

https://doi.org/10.14704/nq.2015.13.1.780

Trojaola-Zapirain, B., Carminati, F., Gonzalez Torres, A., Gonzales de Mendivil, E., Fouassier, C., Gex-Fabry, M., Martin, F., Labarere, J., Demongeot, J., Lorincz, E. N., \& Galli Carminati, G. (2016). A Comparison of the Evolution and Entropy of Responses to Picture Choices on an “Absurdum Questionnaire” between Members of Two Different Training Groups. NeuroQuantology, 14, 501-513. https://doi.org/10.14704/nq.2016.14.3.919

Vergopoulos, T. (1983). La sensibilisation à la dynamique de groupe d'aprés W. R. Bion et S.H. Foulkes. Médecine et Hygiène, 1, 3149-3155.

Vitiello, G. (2003). Quantum Dissipation and Information: A Route to Consciousness Modelling. NeuroQuantology, 1, 266-279. https://doi.org/10.14704/nq.2003.1.2.15

Zanello, A., Rouget-Weber, B., Gex Fabry, M. G., Maercker, A., \& Guimon, J. (2004). New Instrument to Assess Social Functioning in Mental Health Settings. European Journal of Psychiatry, 18, 76-78.

Zurek, H. (1981). Pointer Basis of Quantum Apparatus: Into What Mixture Does the Wave Packet Collapse? Physical Review D, 24, 1516-1525.

https://doi.org/10.1103/PhysRevD.24.1516 